\title{
Pharmacokinetics of Core-Polymerized, Boron-Conjugated Micelles Designed for Boron Neutron Capture Therapy for Cancer
}

Shogo Sumitani ${ }^{\text {a }}$, Motoi Oishi ${ }^{\text {a }}$, Tatsuya Yaguchi ${ }^{\text {a }}$, Hiroki Murotani ${ }^{\text {a }}$, Yukichi Horiguchi ${ }^{\text {a }}$, Minoru Suzuki $^{\mathrm{d}}$, Koji Ono ${ }^{\mathrm{d}}$, Hironobu Yanagie ${ }^{\mathrm{e}}$, Yukio Nagasaki ${ }^{\mathrm{a}, \mathrm{b}, \mathrm{c}^{*}}$

*Corresponding author: Tel: (+81)-29-853-5749, Fax: (+81)-29-853-5749, e-mail address: yukio@ nagalabo.jp

a. Department of Materials Science, Graduate School of Pure and Applied Sciences, University of Tsukuba, Tennoudai 1-1-1, Tsukuba, Ibaraki 305-8573, Japan

b. Master's School of Medical Sciences, Graduate School of Comprehensive Human Sciences, University of Tsukuba, Tennoudai 1-1-1, Tsukuba, Ibaraki 305-8573, Japan

c. Satellite Laboratory, International Center for Materials Nanoarchitectonics (WPI-MANA), National Institute of Materials Science (NIMS), Tennoudai 1-1-1, Tsukuba, Ibaraki 305-8573, Japan

d. Radiation Oncology Research Laboratory, Research Reactor Institute, Kyoto University, Osaka, 2 Asahiro nishi, Kumatori, Sennan, Osaka 590-0494, Japan

e. Department of Nuclear Engineering and Management, School of Engineering, University of Tokyo, 7-3-1 Hongo Bunkyo, Tokyo 113-8655, Japan 


\begin{abstract}
Core-polymerized and boron-conjugated micelles (PM micelles) were prepared by free radical copolymerization of a PEG- $b$-PLA block copolymer bearing an acetal group and a methacryloyl group (acetal-PEG-b-PLA-MA), with 1-(4-vinylbenzyl)-closo-carborane (VB-carborane), and the utility of these micelles as a tumor-targeted boron delivery system was investigated for boron neutron capture therapy (BNCT). Non-polymerized micelles (NPM micelles) that incorporated VB-carborane physically showed significant leakage of VB-carborane (ca. 50\%) after $12 \mathrm{~h}$ incubation with $10 \%$ fetal bovine serum (FBS) at $37^{\circ} \mathrm{C}$. On the other hand, no leakage from the PM micelles was observed even after $48 \mathrm{~h}$ of incubation. To clarify the pharmacokinetics of the micelles, ${ }^{125}$ I (radioisotope)-labeled PM and NPM micelles were administered to colon-26 tumor-bearing BALB/c mice. The ${ }^{125}$ I-labeled PM micelles showed prolonged blood circulation (area under the concentration curve (AUC): 943.4) than the ${ }^{125}$ I-labeled NPM micelles (AUC: 495.1), whereas tumor accumulation was similar for both types of micelles $\left(\mathrm{AUC}_{\mathrm{PM} \text { micelle }}\right.$ : 249.6, $\mathrm{AUC}_{\mathrm{NPM} \text { micelle }}$ : 201.1). In contrast, the tumor accumulation of boron species in the PM micelles (AUC: 268.6) was 7-fold higher than the NPM micelles (AUC: 37.1), determined by ICP-AES. Thermal neutron irradiation yielded tumor growth suppression in the tumor-bearing mice treated with the PM micelles without reduction in body weight. On the basis of these data, the PM micelles represent a promising approach to the creation of boron carrier for BNCT.
\end{abstract}




\section{Introduction}

Boron neutron capture therapy (BNCT) has attracted much attention as a selective and noninvasive type of cancer therapy [1,2]. This therapy is based on the capture reaction of thermal neutrons using nonradioactive ${ }^{10} \mathrm{~B}$, which produces $\alpha$ particles and ${ }^{7} \mathrm{Li}$ nuclei with approximately $2.3 \mathrm{MeV}$ of energy. These high linear-energy-transfer (LET) particles dissipate their energy before traveling across the diameter of cells $(5-9 \mu \mathrm{m})$ within tissues, resulting in cytotoxic effects. Two types of ${ }^{10} \mathrm{~B}$-compunds, sodium borocaptate (BSH) and L-4-dihydroxyboronylphenylalanine (BPA), have been utilized for clinical trials. However, due to the rapid clearance of these compounds from the bloodstream (half-life of blood circulation time of BSH, BPA: $\mathrm{t}_{1 / 2}<1 \mathrm{~h}$ ) [3], a high dose of ${ }^{10} \mathrm{~B}$-compounds is generally required to allow a sufficient concentration of ${ }^{10} \mathrm{~B}$ atoms to accumulate in tumor tissues (BSH: $41 \mathrm{mg}{ }^{10} \mathrm{~B} / \mathrm{kg}, \mathrm{BPA}: 58 \mathrm{mg}{ }^{10} \mathrm{~B} / \mathrm{kg}$ ) [4]. Meanwhile, with BNCT, it is theoretically possible to kill tumor cells without damage to normal cells if ${ }^{10} \mathrm{~B}$ atoms can be selectively accumulated in tumor tissues (15-30 ppm of ${ }^{10} \mathrm{~B}$ atoms per gram of tumor tissue). Therefore, the therapeutic value of cancer BNCT under in vivo conditions is largely dependent on the development of effective boron carrier systems that can achieve modulated disposition in the body through the intravenous route as well as facilitate accumulation in tumor tissues. Maeda and Matsumura reported that large-molecular-weight compounds, including nanoparticles tend to accumulate in tumors due to the presence of leaky neovascular walls and an immature lymphatic system in tumors (a phenomenon called the enhanced permeability and retention (EPR) effect) [5,6]. The high levels of nanoparticle accumulation can be achieved via the EPR effect if the nanoparticle has a tendency for prolonged circulation within the bloodstream, since the EPR effect builds up 
gradually over several days. Thus, prolonged circulation of nanoparticles, for at least several days, in the bloodstream is a preferable feature in development of cancer therapeutics. To improve the therapeutic effect of cancer BNCT, a variety of boron-delivery systems, such as BSH-encapsulated PEG-modified liposomes, have been developed, and some of these can allow accumulation to substantially higher levels in tumor tissues than that achieved with free BSH [7-9]. However, the therapeutic efficacy of BSH-encapsulated liposomes is still controversial due to the leakage of the encapsulated BSH from the liposome into the bloodstream [10]. An alternative approach represented by the ${ }^{10} \mathrm{~B}$-compound-conjugated liposomes fabricated by covalently linking a lipid (hydrophobic group) with a ${ }^{10} \mathrm{~B}$-compound (hydrophilic group) to suppress the leakage of the ${ }^{10} \mathrm{~B}$-compound into the bloodstream $[11,23]$. However, the synthesis of nido-carborane required complicated preparation steps. Additionally, serious acute toxicity was observed in vivo because of the cytotoxicity of nido-carborane [23].

We have studied nano-sized polymeric micelles constructed from AB-type amphiphilic block copolymers as drug carrier and reported the selective accumulation into tumor tissues through the EPR effect [12]. However, one of the disadvantages of utilizing polymeric micelles as the drug carrier was leakage of the drug incorporated in the micelles during blood circulation [13-15]. Therefore, we attempted to prepare polymeric micelles by conjugating the boron compounds through covalent bonds, since release of the incorporated drugs from nanoparticles is not required for BNCT. Recently, we reported the development of a new class of boron delivery systems based on core cross-linked and boron-conjugated micelles prepared by radical polymerization of poly(ethylene glycol)-block-poly(lactide) copolymer (PEG-b-PLA), which bears an acetal group at the PEG end and a methacryloyl group at the biodegradable PLA end (acetal-PEG- $b$-PLA-MA) and 
a polymerizable carborane bearing two vinylbenzyl groups (1,2-bis(4-vinylbenzyl)-closo-carborane) as the cross-linker [16]. Indeed, the obtained core cross-linked and boron-conjugated micelles showed no leakage of boron compounds from the micelles under physiological conditions even in the presence of fetal bovine serum (FBS) at $37^{\circ} \mathrm{C}$, while significant leakage $(80 \%)$ of boron compounds was observed from the non-cross-linked micelles, which incorporate the boron compounds by physical entrapment. The boron concentrations in both blood (13.5\% ID/g) and tumor tissues $(5.4 \% \mathrm{ID} / \mathrm{g})$ of tumor-bearing mice injected with the core cross-linked micelles were significantly higher at $24 \mathrm{~h}$ after the injection than in the mice injected with the non-cross-linked micelles (blood: $1.8 \% \mathrm{ID} / \mathrm{g}$, tumor: $1.4 \% \mathrm{ID} / \mathrm{g}$ ). However, the loading content of the carborane in the micelles was insufficient (ca. $1.0 \mathrm{wt} \%$ ), probably due to low compatibility of the carborane with the micelle core. From calculations made using the pharmacokinetic data, a huge dose $(2,000-3,000$ $\mathrm{mg} / \mathrm{kg}$ ) would be required to attain a therapeutically effective boron concentration in tumor tissue for BNCT (15-30 ppm of ${ }^{10} \mathrm{~B}$ atoms per gram of tumor tissues), if one were to use the core cross-linked micelle. For this reason, it was difficult to utilize the core cross-linked and boron-conjugated micelles as boron carriers for in vivo BNCT.

In this study, we prepared and characterized core-polymerized (but not cross-linked) and boron-conjugated micelles (PM micelles) with high loading content by performing free radical copolymerization of the core of the acetal-PEG- $b$-PLA-MA micelles with polymerizable (mono-functional) 1-(4-vinylbenzyl)-closo-carborane (VB-carborane) as a comonomer (Figure 1). Note that no cross-linking agent was used in the core-polymerization system. The VB-carborane bearing a vinylbenzyl group and a $\mathrm{CH}$ group, was synthesized to increase the loading contents of the boron compounds in the core. Because the $\mathrm{CH}$ group of the carborane has been reported to 
exhibit an acidic nature, the loading occurs when the $\mathrm{CH}$ group of carborane and carbonyl group $(\mathrm{C}=\mathrm{O})$ of the PLA segment interact to form a $\mathrm{C}-\mathrm{H} \cdots \mathrm{O}=\mathrm{C}$ hydrogen bond [17]. PM micelles with high loading content of boron compounds are expected to suppress the leakage of the boron compounds into the bloodstream due to the existence of the covalent bonds between the boron compounds and the PLA core, leading to prolonged blood circulation time and enhanced tumor accumulation. Additionally, the PM micelles are expected to excrete easily from major organs via biodegradation of the PLA core. The PM micelles are thus expected to exert significant therapeutic effects when used with thermal neutron irradiation in tumor-bearing mice because of the high concentration of boron atoms in the tumor tissues, which can be attributed to the high stability of the micelles in the bloodstream. We believe that the use of PM micelles composed of acetal-PEG- $b$-PLA-MA and VB-carborane represents a promising approach to the creation of boron carriers for cancer BNCT.

\section{Materials and methods}

\subsection{Materials}

Azobisisobutironitrile (AIBN; Wako Pure Chemical Industries, Ltd., Osaka, Japan) was purified by recrystallization from methanol and dried in vacuo. $N, N$-Dimethylacetamide (DMAc; Kanto Chemicals Co., Ltd., Tokyo, Japan), o-carborane (Wako Pure Chemical Industries), ${ }^{10} \mathrm{~B}$-enriched $o$-carborane (Katchem spol. s.r.o., Ltd., Prague, Czech), ${ }^{10} \mathrm{~B}$-enriched BSH (Katchem spol. s.r.o., Ltd.) and poly(ethylene glycol) bearing a methoxy group at the $\alpha$ end and a hydroxyl group at the $\omega$ 
end (MeO-PEG-OH) (Fluka Chemie GmbH Co, Germany) were used as received. The molecular weight of the MeO-PEG-OH was 5,000 $\mathrm{g} / \mathrm{mol}$. Water was purified using the Milli-Q system (Millipore). Dynamic light scattering measurements were carried out in phosphate-buffered saline (PBS) at $37{ }^{\circ} \mathrm{C}$ using a Zetasizer Nano-ZS instrument (Malvern, UK) equipped with a $4.0 \mathrm{~mW}$ He-Ne laser $(633 \mathrm{~nm})$. Zeta potential measurement of the micelles was performed at $37^{\circ} \mathrm{C}$ in $5 \mathrm{mM}$ phosphate buffer solution at $\mathrm{pH} 7.4$ using a Zetasizer Nano-ZS. ${ }^{1} \mathrm{H}-\mathrm{NMR}$ spectra were obtained in chloroform- $d$ at $25{ }^{\circ} \mathrm{C}$ with a JEOL EX270 spectrometer (JEOL, Japan). Chemical shifts were reported in ppm relative to $\mathrm{CHCl}_{3}(\delta=7.26 \mathrm{ppm})$. The concentration of boron atoms was determined by inductively coupled plasma atomic emission spectroscopy (ICP-AES) using an ICAP-575 emission spectrometer (Nippon Jarrell-Ash, Japan). Fourier transform infrared spectroscopy (FT-IR) measurements were performed using an FT/IR-300 spectrometer (JASCO, Tokyo, Japan). FT-IR spectra were collected by the $\mathrm{KBr}$ pellet method at a resolution of $4 \mathrm{~cm}^{-1}$ with 128 scans. 1-(4-Vinylbenzyl)-closo-carborane (VB-carborane) was synthesized by a previously reported procedure [18]. The data obtained by elemental analysis, ICP-AES measurement, MS measurement, and ${ }^{1} \mathrm{H}-\mathrm{NMR}$ measurement of VB-carborane are summarized in Supplementary data. Acetal-PEG- $b$-PLA-MA was synthesized as per the method described in our previous report [19], and the molecular weight of the PEG segment and the PLA segment of the block copolymer were estimated to be 5,600 and $5,100 \mathrm{~g} / \mathrm{mol}$, respectively. The detailed characterization data of acetal-PEG- $b$-PLA-MA are summarized in Supplementary data. Acetal-PEG- $b$-PLA-MA micelles were also prepared by the method described in our previous report [19]. The average diameter and size distribution $\left(=\mu_{2} / \Gamma^{2}\right)$ of the acetal-PEG- $b$-PLA-MA micelles were found to be $38.4 \mathrm{~nm}$ and 0.027, respectively, as determined by DLS measurements. Cytotoxicity of the samples was 
evaluated by WST assay as described in Supplementary data.

\subsection{Preparation of PM and NPM micelles}

The core-polymerized and boron-conjugated micelles (PM micelles) were prepared as described previously [16,19]. A solution of VB-carborane $(9.2 \mathrm{mg})$ and AIBN $(0.3 \mathrm{mg})$ in chloroform (1.0 $\mathrm{mL}$ ) was added dropwise to $10 \mathrm{~mL}$ of a stirred aqueous solution of acetal-PEG- $b$-PLA-MA micelles $(2.0 \mathrm{mg} / \mathrm{mL}$ ) to form an $\mathrm{o} / \mathrm{w}$ emulsion. The o/w emulsion was kept for $1 \mathrm{~h}$, and the solution was exposed to air at $25^{\circ} \mathrm{C}$ for $3 \mathrm{~h}$ to evaporate the chloroform, after which the resulting micelle solution was purged with nitrogen gas for 20 min to remove the remaining chloroform and dissolved oxygen completely. To prepare the PM micelles, polymerization was carried out at $60{ }^{\circ} \mathrm{C}$ for $24 \mathrm{~h}$. Purification was carried out by repeated ultrafiltration using a membrane with a molecular weight cut-off of 100,000 (VIVASPIN 4, Sartorius Stedim Biotech, Germany). For comparison, non-polymerized micelles (NPM micelles) encapsulating VB-carborane were prepared by the same procedure as that for PM micelles, without the addition of AIBN and heating. To determine the average diameter and size distribution of the micelles, DLS measurements were carried out in PBS at $37^{\circ} \mathrm{C}$. Zeta potential measurement of the micelles was performed at $37^{\circ} \mathrm{C}$ in $5 \mathrm{mM}$ phosphate buffer solution at $\mathrm{pH}$ 7.4. To check whether the VB-carborane was covalently conjugated the core of the micelles, ${ }^{1} \mathrm{H}-\mathrm{NMR}$ measurements of the lyophilized PM and NPM micelles were carried out in $\mathrm{CDCl}_{3}$ at $25{ }^{\circ} \mathrm{C}$. The loading content and efficiency of the boron atoms in the micelles were determined using ICP-AES. To clarify the interaction between the VB-carborane and the acetal-PEG- $b$-PLA-MA, FT-IR measurements of the VB-carborane, the acetal-PEG- $b$-PLA-MA, the 
MeO-PEG-OH and the mixture of the VB-carborane and the acetal-PEG- $b$-PLA-MA were performed by the KBr pellet method. Degradation of the NPM and PM micelles under the physiological conditions was confirmed by size exclusion chromatography (SEC) analysis using a JASCO HPLC system (JASCO, Tokyo, Japan) equipped with a refractive index (RI) detector (RI-2031) and a Superose 6 10/300 GL column (GE Healthcare, USA) with $10 \mathrm{mM}$ phosphate

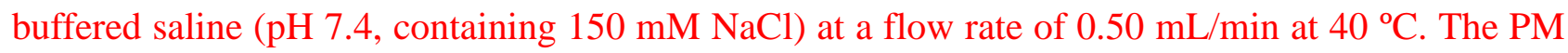
or NPM micelles solution $(1.0 \mathrm{mg} / \mathrm{mL})$ in $10 \mathrm{mM}$ PBS was incubated at $37{ }^{\circ} \mathrm{C}$. At a defined time interval, $50 \mu \mathrm{L}$ aliquots were subjected to SEC system after filtration through $0.45 \mu \mathrm{m}$ filter.

\subsection{Leakage of VB-carborane from PM and NPM micelles}

The leakage of VB-carborane from the PM and NPM micelles was evaluated at $0.23 \mathrm{mg} / \mathrm{mL}$ of micelles, well above the critical association concentration of both the micelles (ca. $2-3 \mu \mathrm{g} / \mathrm{mL}$ ), under physiological conditions and in the presence of $10 \%$ FBS. Briefly, a solution of the PM and NPM micelles $(1.0 \mathrm{mg} / \mathrm{mL}, 3 \mathrm{~mL})$ with $10 \%$ FBS was poured into dialysis bags (MWCO: 100,000), and each bag was immersed in $10 \mathrm{~mL}$ of physiological saline with $10 \% \mathrm{FBS}$ at $37{ }^{\circ} \mathrm{C}$. At a definite time interval, $0.5 \mathrm{~mL}$ of the solution outside the dialysis bag was sampled, and then the solutions were diluted to $20 \mathrm{~mL}$ with distilled water. After filtering through $0.45 \mu \mathrm{m}$ filters (Millipore), ICP-AES measurement of the solution was carried out to determine the amount of VB-carborane released from each micelle based on the concentration of boron atoms, which was determined using a calibration curve based on boric acid (ultratrace analysis grade, Aldrich Chemical Co. Ltd., Milwaukee, WI). 


\subsection{Pharmacokinetics of ${ }^{125}$ I-labeled PM and NPM micelles}

All procedures involving animal care were approved by the Animal Ethics Committee of the University of Tsukuba, and were conducted according to the Guidelines for Animal Experimentation of the University of Tsukuba. To characterize the pharmacokinetics of the micelles, the preparation of the ${ }^{125} \mathrm{I}$ (radioisotope)-labeled PM and NPM micelles was performed according to our previous report $[16,20]$. As described in the previous report, using the acetal group at the end of the PEG chain, a tyrosine residue was introduced as a site of radiolabeling onto the PM or NPM micelles. The detailed procedure is described in Supplementary data. The biodistribution of the ${ }^{125}$ I-labeled PM micelles and ${ }^{125}$ I-labeled NPM micelles was evaluated in tumor-bearing, 5-week-old male BALB/c mice ( $\mathrm{n}=3,20-25 \mathrm{~g}$, Charles River, Japan). Tumors were induced in the mice by subcutaneous injection of colon-26 cells $\left(1.0 \times 10^{6}\right.$ cells/mouse $)$ into the right femur. When the volume of the tumor reached $100 \mathrm{~mm}^{3}$, the ${ }^{125}$ I-labeled PM micelles or ${ }^{125}$ I-labeled NPM micelles were administered to the tumor-bearing mice by intravenous injection at a dose of $0.80 \mathrm{mg}$ boron atoms per kg body weight. Blood, liver, spleen, kidney and tumor samples were collected, using sodium pentobarbital $(40 \mathrm{mg} / \mathrm{kg})$ as an anesthetic, at defined time periods after injection of the micelles. The radioactivity and the weight of the collected samples were measured by a $\gamma$-counter (Aloka, Japan) and a balance, respectively.

\subsection{Pharmacokinetics of boron species in the PM and NPM micelles}


The pharmacokinetics of the boron species (VB-carborane) in the PM and NPM micelles were evaluated in tumor-bearing 5-week-old-male BALB/c mice $(n=3)$ on the basis of the concentration of boron atoms determined using ICP-AES. As a comparison, the pharmacokinetic of ${ }^{10} \mathrm{~B}$-enriched $\mathrm{BSH}$, which is clinically utilized, was also evaluated. The PM micelles, NPM micelles or BSH solution were administered to the tumor-bearing mice by intravenous injection at a dose of $0.80 \mathrm{mg}$ boron atoms per kg body weight. Blood, liver, spleen, kidney and tumor samples were collected at defined time periods after the injection under anesthesia with pentobarbital sodium $(40 \mathrm{mg} / \mathrm{kg})$ and weighted. The freeze-dried tissues were dissolved with $1 \mathrm{~mL}$ of $\mathrm{HNO}_{3}$ (ultratrace analysis grade, Wako, Japan) and $0.5 \mathrm{~mL}$ of hydrogen peroxide solution (ultratrace analysis grade, Kanto Chemicals, Japan) at $60{ }^{\circ} \mathrm{C}$ for $3 \mathrm{~h}$. The dissolved samples were then diluted with distilled water. After filtering through a $0.45 \mu \mathrm{m}$ filter, the concentration of boron atoms in the tissues was measured using ICP-AES. Long-term tissue distribution of boron species in the PM and NPM micelles was also examined in normal 5-week-old-male BALB/c mice. The PM and NPM micelles were administered to the mice by intravenous injection at a dose of $0.80 \mathrm{mg}$ boron atoms per $\mathrm{kg}$ body weight, and the concentration of boron atoms in each tissue was measured using the procedure described above.

\subsection{BNCT for tumor-bearing mice}

Neutron irradiation was carried out in the Japan Research Reactor No. 4 (JRR4) of Japan Atomic Energy Agency and Kyoto University Research Reactor (KUR) of Kyoto University Research Reactor Institute. ${ }^{10} \mathrm{~B}$-enriched $\mathrm{PM}$ and NPM micelles were prepared from ${ }^{10} \mathrm{~B}$-enriched 
VB-carborane and acetal-PEG- $b$-PLA-MA by the same procedure described above. The ${ }^{10} \mathrm{~B}$-enriched PM and NPM micelle solutions was injected into colon-26 tumor bearing mice $(\mathrm{n}=5)$ via the tail vein at a dose of $15.6 \mathrm{mg}{ }^{10} \mathrm{~B} / \mathrm{kg} 24 \mathrm{~h}$ before irradiation. For comparison, ${ }^{10} \mathrm{~B}$-enriched BSH solution was injected $1 \mathrm{~h}$ before irradiation via the tail vein at a dose of $30.0 \mathrm{mg}{ }^{10} \mathrm{~B} / \mathrm{kg}$. The mice were anesthetized with pentobarbital sodium $(40 \mathrm{mg} / \mathrm{kg})$ and placed in an acrylic mouse holder. They were then irradiated in the JRR4 and KUR at a rate of $1.6-1.8 \times 10^{12}$ neutrons $/ \mathrm{cm}^{2}$. The effects of BNCT were evaluated in terms of the tumor size, which was estimated by using the following equation: $\mathrm{V}=(\mathrm{a}) \times(\mathrm{b})^{2} / 2$, where (a) and (b) are major and minor axes of the tumor measured by a caliper, respectively. Body weight was measured as an indicator of systemic toxicity.

\section{Results and discussions}

\subsection{Preparation and characterization of PM and NPM micelles}

The acetal-PEG- $b$-PLA-MA was synthesized as described in our previous paper [19], and the molecular weights of the PEG and PLA segments of the block copolymer were estimated to be 5,600 and $5,100 \mathrm{~g} / \mathrm{mol}$, respectively. The detailed characterization data of the acetal-PEG- $b$-PLA-MA are summarized in Supplementary data. The VB-carborane was synthesized using a previously reported procedure [18] and is described in detail in Supplementary data. To prepare the acetal-PEG- $b$-PLA-MA micelles, the dialysis method was employed as described previously [19]. The average diameter of the acetal-PEG- $b$-PLA-MA micelles was $38.4 \mathrm{~nm}$ with a narrow size distribution $\left(\mu_{2} / \Gamma^{2}=0.027\right)$, as determined by DLS measurement (Figure S4). To 
prepare the NPM micelles, the VB-carborane was encapsulated into acetal-PEG- $b$-PLA-MA micelles by means of the solvent evaporation method. The average diameter of the VB-carborane encapsulating acetal-PEG- $b$-PLA-MA micelles (NPM micelles) increased from $38.4 \mathrm{~nm}$ to $60.2 \mathrm{~nm}$ with a narrow size distribution $\left(\mu_{2} / \Gamma^{2}=0.119\right)$, as shown in Figure S4. This is probably due to the formation of a loosely associated PLA core as a result of the swelling of the hydrophobic PLA core, which occurs upon the addition of chloroform, as previously reported [19]. To prepare the PM micelles, both VB-carborane and AIBN were encapsulated into acetal-PEG- $b$-PLA-MA micelles by means of the solvent evaporation method, and the polymerization of the core was carried out at $60^{\circ} \mathrm{C}$ for $24 \mathrm{~h}$. The characteristics of the PM and NPM micelles are summarized in Table 1. The average diameter $\left(67.3 \mathrm{~nm}, \mu_{2} / \Gamma^{2}=0.113\right)$ and zeta-potential $(-0.32 \pm 0.99 \mathrm{mV})$ of the PM micelles was almost similar to that of the NPM micelles $\left(60.2 \mathrm{~nm}, \mu_{2} / \Gamma^{2}=0.119\right.$, zeta-potential: $-0.15 \pm 0.05$ $\mathrm{mV}$ ), suggesting that the core polymerization process does not influence the size distribution and the zeta-potential of the micelles. To confirm that the VB-carborane was covalently linked with the end of the PLA chain, ${ }^{1} \mathrm{H}-\mathrm{NMR}$ measurements of the lyophilized NPM and PM micelles were carried out in $\mathrm{CDCl}_{3}$, which is a good solvent for both acetal-PEG-b-PLA-MA and VB-carborane (Figure S5). In the spectrum obtained for the NPM micelles, peaks at 5.60 and $6.20 \mathrm{ppm}$ were observed, which can be attributed to the methacryloyl group at the end of PLA chain, and peaks for the vinyl protons of VB-carborane were observed at $5.70 \mathrm{ppm}$. These data indicate that both acetal-PEG- $b$-PLA-MA and VB-carborane were dissolved in $\mathrm{CDCl}_{3}$. On the other hand, the peaks attributed to the methacryloyl and vinyl groups were reduced by more than $99 \%$ in the spectrum obtained for the PM micelles, suggesting that the copolymerization of the acetal-PEG- $b$-PLA-MA and VB-carborane proceeded successfully. The loading content of VB-carborane in the NPM and 
PM micelles was determined to be $8.5 \mathrm{wt} \%$ (loading efficiency: $23.5 \%$ ) and $7.7 \mathrm{wt} \%$ (loading efficiency: $21.5 \%$ ), respectively. The loading content of both micelles was comparable, indicating that leakage of VB-carborane from the micelles did not occur during the polymerization process. It is of note that the loading content of VB-carborane in the acetal-PEG- $b$-PLA-MA micelles (ca. 1.0 wt\%) increased remarkably in comparison with that in polymerizable carborane bearing two vinylbenzyl groups (1,2-bis(4-vinylbenzyl)-closo-carborane) [16]. This increment might be caused by the enhancement of the compatibility of the VB-carborane with the PLA core of the micelles due to the existence of the hydrogen bonds between the $\mathrm{CH}$ group of the $\mathrm{VB}$-carborane and the $\mathrm{O}$ atom of the carbonyl group $(\mathrm{C}=\mathrm{O})$ in the PLA segments. To clarify the interaction between the VB-carborane and the acetal-PEG- $b$-PLA-MA, FT-IR measurements of the VB-carborane, the acetal-PEG- $b$-PLA-MA, the MeO-PEG-OH and the mixture of the VB-carborane and the acetal-PEG- $b$-PLA-MA were performed by the $\mathrm{KBr}$ pellet method. The VB-carborane spectrum shows the characteristic peaks of VB-carborane at $2578 \mathrm{~cm}^{-1}(v(\mathrm{~B}-\mathrm{H}))$ and $3070 \mathrm{~cm}^{-1}(v(\mathrm{C}-\mathrm{H}))$ (Figures 2(A)(a) and 2(B)(a)). The peak of the $\mathrm{CH}$ group of the VB-carborane was also observed at the same wavenumber $\left(3071 \mathrm{~cm}^{-1}\right)$ in the spectrum of the mixture of the MeO-PEG-OH and the VB-carborane (Figure 2(A)(c)). This indicates that there might be no interaction between the $\mathrm{CH}$ group of the VB-carborane and PEG chains. On the other hand, the peak of the $\mathrm{CH}$ group of the VB-carborane was shifted to $3057 \mathrm{~cm}^{-1}$ in the spectrum of the mixture of the acetal-PEG- $b$-PLA-MA and the VB-carborane (Figure 2(B)(c)). This result strongly indicates the existence of the hydrogen bonds between the $\mathrm{CH}$ group of the VB-carborane and the $\mathrm{O}$ atom of the carbonyl group $(\mathrm{C}=\mathrm{O})$ in the PLA segments, because shifting of the peak of the $\mathrm{CH}$ group of carboranes in the presence of the hydrogen bond of the $\mathrm{C}-\mathrm{H}^{\cdots} \mathrm{O}=\mathrm{C}$ has been reported previously 
[21]. From these results, we concluded that the interaction between carborane and PLA chain via hydrogen bonds might be one of the reasons for the higher loading content of the carborane. Degradation of the NPM and PM micelles were analyzed using a SEC system equipped with a RI detector and a Superose 6 10/300 GL column. As shown in Figures S6(a) and (b), the peaks attributed to the NPM and PM micelles were observed by RI detection at $16 \mathrm{~min}$ in the region of the exclusion limit $\left(M_{\mathrm{n}}>300,000\right)$ at 0 day after incubation. After several days incubation, the peaks were appeared at $23 \min \left(M_{\mathrm{n}}=\right.$ ca. 5,400) attributed to free PEG and the micellar peaks decreased in both charts of the NPM and PM micelles dependent the incubation days. Consequently, both the NPM and PM micellar peaks were disappeared completely after 19 and 25 days incubation, respectively. These results strongly indicate that the PM micelles were able to be degraded via biodegradation under the physiological conditions similarly the NPM micelles even though the core of the micelles was polymerized.

It has been reported that certain types of hydrophobic compounds incorporated in polymeric micelles by physical entrapment are leaked rapidly after they are administered by intravenous injection due to the interaction, and this rapid leakage occurs between the micelles and some blood components [13-15]. The leakage of the boron compounds, which are encapsulated in the micelles, is potentially toxic to the normal tissues after the irradiation of the thermal neutrons in BNCT. In our previous report, the leakage of polymerizable carborane bearing two vinylbenzyl groups (1,2-bis(4-vinylbenzyl)-closo-carborane) from the non cross-linked micelles occurred immediately under physiological conditions in the presence of $10 \% \mathrm{FBS}$, whereas the cross-linked micelles showed complete suppression of carborane leakage under the same conditions, which can be attributed to the covalent bonds between the boron compounds and the PLA segments in the 
micellar core [16]. In this study, the VB-carborane bearing a vinylbenzyl group and a $\mathrm{CH}$ group was loaded in the micelles. In order to confirm the stability of the PM and the NPM micelles under physiological conditions, the leakage of VB-carborane from both micelles was evaluated by dialysis at $37^{\circ} \mathrm{C}$ in PBS with $10 \% \mathrm{FBS}$, as shown in Figure 3. The amounts of leaked VB-carborane from the micelles were determined by ICP-AES, and the results were based on the concentration of boron atoms in the solution of the outside of dialysis bags. Significant amounts (ca. 50\%) of VB-carborane had leaked from the NPM micelles after $12 \mathrm{~h}$. This means that the stability of the VB-carborane physically entrapped in the acetal-PEG- $b$-PLA-MA micelles was insufficient under physiological conditions in the presence of serum proteins, even though there were interactions between VB-carborane and the PLA core. In sharp contrast, the PM micelles showed no leakage of the VB-carborane even after $48 \mathrm{~h}$, likely due to the existence of covalent bonds between VB-carborane and the PLA core. From these facts, we conclude that covalent conjugation, rather than physical entrapment, is required for in vivo stabilization in the case of VB-carborane. The cytotoxicity of the PM micelles, NPM micelles, and VB-carborane against colon-26 cells was evaluated in the presence of 10\% FBS in the cell culture medium as shown in Figure S8. Note that the PM micelles showed no toxicity even at high concentration $([\mathrm{B}]=10 \mathrm{mM})$. In contrast, $50 \%$ inhibitory concentration $\left(\mathrm{IC}_{50}\right)$ values of the NPM micelles and VB-carborane were $4.3 \mathrm{mM}$ and 1.4 $\mathrm{mM}$, respectively. Moreover, the cytotoxicity of the VB-carborane is lower than the nido-carborane derivative $\left(\mathrm{IC}_{50}=0.5 \mathrm{mM}\right)$ [24] which has been used in the ${ }^{10} \mathrm{~B}$-compound-conjugated liposomes $[11,23]$. Notably that the cytotoxicity of the PM micelles $\left(\mathrm{IC}_{50}=\right.$ not determined $)$ was significantly lower than that of the NPM micelles $\left(\mathrm{IC}_{50}=4.3 \mathrm{mM}\right)$. These results indicate that the leakage of the VB-carborane from the NPM micelles occurred in the presence of $10 \%$ FBS, leading to the 
cytotoxicity caused by the free VB-carborane. In sharp contrast, the leakage of VB-carborane from the PM micelles was suppressed even in the presence of 10\% FBS because the VB-carborane was conjugated with the core of micelles through the covalent bonds. It can be concluded that the PM micelle system is utilized for BNCT from the standpoint of the cytotoxicity. It is important to note that the present synthetic method is simple modification of a well-known emulsion polymerization technique. Thus, large scale production with reproducible manner of ${ }^{10} \mathrm{~B}$-enriched PM micelle is strongly anticipated for clinical trials in future.

\subsection{Pharmacokinetics studies of the micelles and boron species}

In a recent study, we found that compared to the non cross-linked micelles physically encapsulating the carboranes, the core cross-linked and boron-conjugated micelles prepared by polymerization of acetal-PEG- $b$-PLA-MA with polymerizable carborane bearing two vinylbenzyl groups (1,2-bis(4-vinylbenzyl)-closo-carborane) showed higher tumor accumulation of boron species at $24 \mathrm{~h}$ after injection, although the tumor accumulation of both micelles at $24 \mathrm{~h}$ after injection was similar [16]. This means that the distribution of boron species (carboranes) in the cross-linked and non cross-linked micelles was different, perhaps due to the leakage of the carborane into the bloodstream. In this study, we performed pharmacokinetic measurements, to clarify the distribution of both the micelles and the boron species after injection.

The micelle and boron concentrations in various tissues, such as liver, kidney, spleen, tumor, and blood, were measured at defined time periods after their injection into tumor-bearing mice. For the pharmacokinetics study of the micelles, a radioisotope $\left({ }^{125} \mathrm{I}\right)$ was introduced at the end of the 
PEG-chain after L-tyrosine installation, as described in our previous report $[16,20]$. The acetal groups at the end of PEG chains on the micelles were de-protected through acid treatment to convert the reactive aldehyde groups, and this was followed by the addition of L-tyrosine hydrazide and sodium cyanoborohydride as a reductant. ${ }^{125}$ I-labeling was performed using the conventional chloramine T method (Supplementary data, Figure S7). The radioactivity level of the ${ }^{125}$ I-labeled PM and NPM micelles in each of tissues and blood were expressed as a percentage of the injected dose per gram tissue $(\% \mathrm{ID} / \mathrm{g})$ at specified times after intravenous injection in tumor-bearing mice, as shown in Figures $\mathbf{4}$ and S9. The area under concentration curve (AUC) values in each tissue at $48 \mathrm{~h}$ after injection, and the AUC ratios (PM/NPM) are summarized in Table 2. Note that 9.5\%ID/g of ${ }^{125}$ I-labeled PM micelles remained in the bloodstream after $48 \mathrm{~h}$, whereas only $5.6 \% \mathrm{ID} / \mathrm{g}$ of ${ }^{125}$ I-labeled NPM micelles remained $48 \mathrm{~h}$ after injection (Figure 4(a)). The AUC value of the ${ }^{125}$ I-labeled PM micelles in blood (943.4) was higher than that of the ${ }^{125}$ I-labeled NPM micelles (495.1) (AUC ratio: 1.91). Additionally, the ${ }^{125} \mathrm{I}$-labeled NPM micelles $(8.2 \% \mathrm{ID} / \mathrm{g}$ ) showed higher radioactivity levels than the ${ }^{125}$ I-labeled PM micelles $(3.2 \% \mathrm{ID} / \mathrm{g}$ ) in the kidney after $1 \mathrm{~h}$ (Figure S9(c)), indicating that a portion of the NPM disintegrated in the bloodstream and was excreted via the renal pathway. In contrast, the PM micelles showed extremely high stability in the bloodstream due to the covalent conjugation of the PLA segment in the micelles with VB-carborane. The longer circulation times of these micelles are suitable for accumulation in tumor regions via the EPR effect. The AUC values of the ${ }^{125}$ I-labeled PM micelles in both liver (619.1) and spleen (581.0) were slightly higher than those of the ${ }^{125}$ I-labeled NPM micelles (liver: 350.7, spleen: 409.6). These increments are probably due to the prolongation of the blood circulation time of the ${ }^{125}$ I-labeled PM micelles. In contrast, there were no significant differences in the radioactivity levels in the tumor 
(AUC ratio (PM/NPM): 1.24) between the ${ }^{125}$ I-labeled PM micelles and the ${ }^{125}$ I-labeled NPM micelles (Figure 4(b)). These results mean that the effects of micelle core-polymerization on the pharmacokinetics were similar to those of micelle core-cross linking, consistent with our previous report [16].

In order to confirm the pharmacokinetics of the boron species in the tumor-bearing mice after injection of the PM micelles, the NPM micelles and BSH, the concentration of boron atoms in tissues was evaluated using ICP-AES. Figures 5 and S10 show the distribution of boron species in the tumor-bearing mice after the injection of the PM micelles, the NPM micelles and free BSH. The concentrations of the boron atoms in each of the tissues and blood at specific times after the intravenous injection are expressed as $\% \mathrm{ID} / \mathrm{g}$, as determined by ICP-AES. The AUC values of boron species in each of the tissues and blood after injection and the corresponding AUC ratios (PM/NPM) are summarized in Table 3. The boron species of both NPM micelles $(1.1 \% \mathrm{ID} / \mathrm{g})$ and PM micelles (4.6\% ID/g) remained in the bloodstream even $48 \mathrm{~h}$ after the injection, whereas over $99 \%$ of the injected dose of free BSH was immediately eliminated from the bloodstream by renal clearance, because the amounts of $\mathrm{BSH}$ accumulated in the kidney $1 \mathrm{~h}$ after the injection $(22.8 \% \mathrm{ID} / \mathrm{g})$ were apparently higher than those of both the NPM $(12.6 \% \mathrm{ID} / \mathrm{g})$ and the PM micelles (5.1\% ID/g) (Figures 5(a) and S10(c)). The post-injection AUC value of PM micelles in blood (916.0) was 2.8-fold higher than that of the NPM micelles (330.4). These data indicate that the blood circulation time of boron species in the PM micelles was prolonged, likely due to the covalent conjugation of VB-carborane to the micelle core matrix. It has also been shown that a large amount of VB-carborane is leaked from the NPM micelles into the bloodstream due to the interaction with the serum proteins. The distribution of the boron species of the NPM micelles in kidney at $1 \mathrm{~h}$ after 
injection $(12.6 \% \mathrm{ID} / \mathrm{g})$ was 2.5 -fold higher than that of the PM micelles $(5.1 \% \mathrm{ID} / \mathrm{g})($ Figure S10(c)), and higher than those of the ${ }^{125} \mathrm{I}$-labeled NPM micelles $(8.2 \% \mathrm{ID} / \mathrm{g})$. These data suggest that the VB-carborane was leaked from the NPM micelles easily, and eliminated from the bloodstream more readily than the micelles (polymers) by renal clearance, due to the low-molecular weight of NPM micelles. Figure 5(b) shows the tumor accumulation amounts of boron species in the PM micelles, the NPM micelles and free BSH. The accumulation level of boron species in the tumor tissues of the mice treated with the PM micelles was 5.7\% ID/g at $48 \mathrm{~h}$ after the injection, whereas those of the NPM micelles at $48 \mathrm{~h}$ and free BSH at $1 \mathrm{~h}$ after the injection were only $0.7 \% \mathrm{ID} / \mathrm{g}$ and $1.6 \% \mathrm{ID} / \mathrm{g}$, respectively. Note that the AUC ratio (PM/NPM) of the boron species of the micelles in tumor tissues (AUC ratio: 7.29) was remarkably higher than that of the ${ }^{125}$ I-labeled micelles (AUC ratio: 1.24) (Tables $\mathbf{2}$ and 3). It should be noted that the PM micelles were remained in the tumor tissues for $48 \mathrm{~h}$ after the injection by EPR effect, whereas BSH was excreted from the tumor rapidly. This indicates that there is enough time to precisely determine the ${ }^{10} \mathrm{~B}$ concentration by several techniques after injection of the $\mathrm{PM}$ micelles because the ${ }^{10} \mathrm{~B}$ concentration in tumor is constant for several days, suggesting that the effective radiation of the thermal neutrons is permitted by utilizing the PM micelles. Using the obtained data, tumor-to-blood (T/B) ratios of the boron concentration in the tumor-bearing mice were determined as a function of time as shown in Figures 6. Although no remarkable difference between the T/B ratios of the micelles, viz., the PM and NPM micelles was observed as shown in Figure 6(a), a significant difference in T/B ratio was observed in terms of the boron species. For example, the T/B ratio of boron species increased gradually up to $48 \mathrm{~h}$ when the PM micelle was used as the carrier, while it did not increase with the NPM micelle (Figure 6(b)). These data strongly suggest that in the case of PM micelles, the VB-carborane and 
the micelles concomitantly accumulated in tumor tissues because of the covalent conjugation of the VB-carborane with the block copolymer. On the other hand, the VB-carborane in the NPM micelles was leaked easily during circulation in the bloodstream after the injection, leading to lower accumulation of boron species than that of the micelles in tumor tissues. These results strongly indicate that the PM micelles were sutable boron carriers for tumor regions due to the high stability in the bloodstream. Further improvement in tumor accumulation is now under investigation and will be publish elsewhere.

We have demonstrated the high accumulation tendency of the boron-conjugated PM micelles to tumor regions by performing covalent conjugation of VB-carborane to the core of the micelles. Because the covalent conjugation of the core of the micelles via VB-carborane increases the molecular weight of the matrix, it may also alter the excretion of the PM micelles from the body. Long-term accumulation of certain types of nanoparticles in the body often causes unexpected toxicity [22]. Long-term distribution of boron species in major tissues (blood, liver, spleen, and kidney) after intravenous injection of the PM and NPM micelles was investigated up to two weeks using normal mice. As can be seen in Figure 7, both boron species in the PM and NPM micelles were almost completely eliminated from major organs at $7 \mathrm{~d}$ after injection, which was determined by the ICP-AES measurements. Even though VB-carborane was conjugated covalently in the core of the PM micelles, almost complete excretion of the boron species was confirmed, which was probably caused by hydrolysis of the ester linkage in the PLA segment. These results strongly suggest that the PM micelles are useful not only for enhancing their selective accumulation in tumor tissues, but also for promoting the safety of the micelles. 


\subsection{BNCT for tumor-bearing mice}

The effects of ${ }^{10} \mathrm{~B}$-enriched PM micelles, NPM micelles and BSH on tumor growth suppression were examined with thermal neutron irradiation. The ${ }^{10} \mathrm{~B}$-enriched PM and NPM micelles were prepared from ${ }^{10} \mathrm{~B}$-enriched VB-carborane by means of the same procedure as for the PM, NPM micelles described above. The average diameter of the ${ }^{10} \mathrm{~B}$-enriched PM micelles $\left(61.0 \mathrm{~nm}, \mu_{2} / \Gamma^{2}=\right.$ $0.120)$ and ${ }^{10} \mathrm{~B}$-enriched NPM micelles $\left(60.6 \mathrm{~nm}, \mu_{2} / \Gamma^{2}=0.101\right)$ were similar to those of the PM micelles $\left(67.3 \mathrm{~nm}, \mu_{2} / \Gamma^{2}=0.113\right)$ and the NPM micelles $\left(60.2 \mathrm{~nm}, \mu_{2} / \Gamma^{2}=0.119\right)$ prepared using naturally abundant VB-carborane. The ${ }^{10} \mathrm{~B}$ atoms concentrations in each tissue (blood, liver, spleen, kidney, and tumor) of the tumor-bearing mice at $24 \mathrm{~h}$ after injecting the ${ }^{10} \mathrm{~B}$-enriched PM or NPM micelles were determined using ICP-AES (Figure 8). The ${ }^{10} \mathrm{~B}$ atoms concentration at $24 \mathrm{~h}$ after injection of the ${ }^{10} \mathrm{~B}$-enriched PM micelles in the tumor $(14.0 \mathrm{ppm})$ was about 4.2-fold higher than that of the ${ }^{10} \mathrm{~B}$-enriched NPM micelles $(3.3 \mathrm{ppm})$, suggesting that the high colloidal stability of ${ }^{10} \mathrm{~B}$-enriched PM micelles in the blood stream increased its accumulation in the tumor region via the EPR effect. Since the highest accumulation of boron species in tumor tissues was observed at $1 \mathrm{~h}$ after injecting $\mathrm{BSH}$ as described above (Figure $\mathbf{5}(\mathbf{b})$ ), the ${ }^{10} \mathrm{~B}$ atoms concentration in each tissue was evaluated at $1 \mathrm{~h}$ after injecting $\mathrm{BSH}$ (Figure 8). The result shows that the ${ }^{10} \mathrm{~B}$ atoms concentration in the tumor at $1 \mathrm{~h}$ after injecting $\mathrm{BSH}$ was reached $12.3 \mathrm{ppm}$. From the obtained data on PM, NPM micelles and BSH, it is indicated that the sufficient ${ }^{10} \mathrm{~B}$ atoms concentration was achieved after injecting the ${ }^{10} \mathrm{~B}$-enriched PM micelles even at a half dose of $\mathrm{BSH}\left({ }^{10} \mathrm{~B}\right.$-enriched PM micelles: $15.6{ }^{10} \mathrm{~B} \mathrm{mg} / \mathrm{kg}$, BSH: $30.0{ }^{10} \mathrm{~B} \mathrm{mg} / \mathrm{kg}$ ). As stated above, the distributed PM micelles in normal organs were confirmed to eliminate completely within 7 days after injection (Figure 7(a)), 
indicating no further concern on the serious issues in term of toxicity. It should be also emphasized that the ${ }^{10} \mathrm{~B}$-enriched PM micelles and the ${ }^{10} \mathrm{~B}$-enriched NPM micelles showed no acute toxicity even at a dose of $15.6 \mathrm{mg}{ }^{10} \mathrm{~B} / \mathrm{kg}$, while nido-carborane conjugated liposome showed strong acute toxicity within one day even at a dose of $6.0 \mathrm{mg}{ }^{10} \mathrm{~B} / \mathrm{kg}[23]$.

Figure 9 shows the changes in the tumor volume of mice bearing colon-26 tumors $(n=5)$ with thermal neutron irradiation for $37 \min \left(1.6-1.8 \times 10^{12}\right.$ neutrons $\left./ \mathrm{cm}^{2}\right)$ after injecting the ${ }^{10} \mathrm{~B}$-enriched PM, NPM micelles, free BSH, or normal saline. The tumor growth in mice treated with the ${ }^{10} \mathrm{~B}$-enriched PM micelles without irradiation was similar to that in mice treated with normal saline without the irradiation. This indicates that the ${ }^{10} \mathrm{~B}$-enriched PM micelles alone and the thermal neutron irradiation alone did not suppress the tumor growth. Additionally, no suppression of the tumor growth was observed in the mice treated with the ${ }^{10} \mathrm{~B}$-enriched NPM micelles with the irradiation of the thermal neutrons due to the insufficient concentration of the ${ }^{10} \mathrm{~B}$ atoms in the tumor tissues (3.3 ppm). In sharp contrast, significant suppression of tumor growth was observed in the mice treated with the ${ }^{10} \mathrm{~B}$-enriched PM micelles with thermal neutron irradiation, after 12 days $(p<0.01)$. Consequently, at day 25,2 of 5 tumors disappeared completely in the mice treated with the ${ }^{10} \mathrm{~B}$-enriched PM micelles. Even though the concentration of ${ }^{10} \mathrm{~B}$ atoms in tumor tissues of the mice (14.0 ppm) treated with the ${ }^{10} \mathrm{~B}$-enriched PM micelles was almost equal to the concentration in mice treated with BSH (12.3 ppm), the ${ }^{10} \mathrm{~B}$-enriched PM micelles showed significant therapeutic effects after neutron irradiation, compared to those shown by BSH. These data might indicate that BSH was extracted from tumor tissues during the irradiation $(37 \mathrm{~min})$ due to the short retention time of BSH in tumor tissues $(<1 \mathrm{~h}$ ) as described above (Figure $\mathbf{5}(\mathbf{b}))$. In contrast, the ${ }^{10} \mathrm{~B}$ atoms were able to remain in the tumor tissues of the mice treated with the ${ }^{10} \mathrm{~B}$-enriched PM micelles for at least 
$48 \mathrm{~h}$ by the EPR effect, consistent with the pharmacokinetics study (Figure 5(b)). These results strongly suggest that the retention of ${ }^{10} \mathrm{~B}$ atoms for longer times in tumor tissues is an important factor for achieving beneficial therapeutic effects in BNCT. Figure $\mathbf{1 0}$ shows the time course of body weight change in mice bearing colon-26 tumor $(\mathrm{n}=5)$ with thermal neutron irradiation for 37 min after treatment with ${ }^{10} \mathrm{~B}$-enriched PM micelles, ${ }^{10} \mathrm{~B}$-enriched NPM micelles, free $\mathrm{BSH}$, or normal saline. The mice treated with ${ }^{10} \mathrm{~B}$-enriched PM micelles, ${ }^{10} \mathrm{~B}$-enriched NPM micelles and normal saline showed no significant body weight loss compared to the starting weight. On the basis of these results, we conclude that the ${ }^{10} \mathrm{~B}$-enriched PM micelles are suitable candidates for boron carriers in cancer BNCT, and that they exhibit beneficial therapeutic effects without any side-effects. Further study on the precise influence of the irradiation against normal organs is currently underway in our laboratory.

\section{Conclusion}

In this study, PM micelles composed of acetal-PEG- $b$-PLA-MA and VB-carborane were prepared to suppress non-specific release of boron compounds into the bloodstream. The PM micelles were able to incorporate the high amounts of boron compounds. The release of VB-carborane from the PM micelles was completely suppressed in the presence of FBS due to the introduction of covalent bonds between the VB-carborane and the PLA core. Additionally, the PM micelles showed prolonged blood circulation time and enhanced accumulation of boron species in tumor tissues, in compared with the NPM micelles. Both boron species in the PM and NPM micelles were 
eliminated completely from the body within 7 days after the intravenous injection. It is worth noticing that the ${ }^{10} \mathrm{~B}$-enriched PM micelles showed remarkable therapeutic efficacy in BNCT; viz, selective and non-invasive BNCT was achieved. Therefore, the ${ }^{10} \mathrm{~B}$-enriched PM micelles represent a promising approach to the creation of boron carriers for cancer BNCT. Additionally, the ${ }^{10} \mathrm{~B}$-enriched PM micelles are expected to be accommodated patient treatments since the procedures to prepare the micelles require simple processes.

\section{Acknowledgements}

This work was partially supported by a Grant-in-Aid for Scientific Research on Innovative Areas “Molecular Soft-Interface Science” (\#20106011), from the Ministry of Education, Culture, Sports, Science and Technology of Japan (MEXT). This work has been performed by using facilities of the Research Reactor Institute, Kyoto University and the Japan Atomic Energy Agency. One of the authors (SS) wishes to express his sincere appreciation of the Research Fellowships of the Japan Society for the Promotion of Science for Young Scientists.

\section{Appendix. Supplementary data}

Supplementary data related to this article can be found online. 


\section{References}

[1] Barth RF, Soloway AH, Fairchild RG, Brugger RM. Cancer 1992; 70: 2995-3007.

[2] Barth RF, Coderre JA, Vincent MGH, Blue TE. Clin Cancer Res 2005; 11: 3987-4002.

[3] Ichikawa H, Taniguchi E, Fujimoto T, Fukumori Y. Appl Radiat Isot 2009; 67: 111-114.

[4] Ono K, Masunaga S, Suzuki M, Kinashi Y, Takagaki M, Akaboshi M. Int J Radiat Oncol Biol Phys 1999; 43: 431-436.

[5] Matsumura Y, Maeda H. Cancer Res 1986; 46: 6387-6392.

[6] Maeda H, Sawa T, Konno T. J Control Release 2001; 74: 47-61.

[7] Mehta SC, Lai JCK, Lu DR. J Microencapsul 1996; 13: 269-279.

[8] Maruyama K, Ishida O, Kasaoka S, Takizawa S, Utoguchi N, Shinohara A, Chiba M, Kobayashi H, Eriguchi M, Yanagie H. J Control Release 2004; 98: 195-207.

[9] Yanagie H, Maruyama K, Takizawa T, Ishida O, Ogura K, Matsumoto T, Sakurai K, Kobayashi T, Shinohara A, Rant J, Skvarc J, Ilic R, Kuhne G, Chiba M, Furuya Y, Sugiyama H, Hisa T, Ono K, Kobayashi H. Eriguchi M. Biomed Pharmacother 2006; 60: 43-50.

[10] Feakes DA, Shelly K, Hawthorne MF. Proc Natl Acad Sci USA 1995; 92: 1367-1374.

[11] Miyajima Y, Nakamura H, Kuwata Y, Lee JD, Masunaga S, Ono K, Maruyama K. Bioconjug chem 2006; 17: 1314-1320.

[12] Kataoka K, Harada A, Nagasaki Y. Adv Drug Deliv Rev 2001; 47: 113-131.

[13] Burt HM, Zhang X, Toleikis P, Embree L, Hunter WL. Colloids Surf B Biointerfaces 1999; 16: $161-171$.

[14] Chen H, Kim S, He W, Wang H, Low PS, Park K, Cheng JX. Langmuir 2008; 24: 5213-5217. 
[15] Diezi TA, Bae Y, Kwon GS. Mol pharm 2010; 7: 1355-1360.

[16] Sumitani S, Oishi M, Nagasaki Y. React Funct Polym 2011; 71: 684-693.

[17] Davidson MG, Hibbert TG, Howard JAK, Mackinnon A, Wade K. Chem Commun 1996; 19: 2285-2286.

[18] Benhabbour SR, Parrott MC, Gratton SEA, Adronov A. Macromolecules 2007; 40: 5678-5688.

[19] Iijima M, Nagasaki Y, Okada T, Kato M, Kataoka K, Macromolecules 1999; 32: 1140-1146.

[20] Yamamoto Y, Nagasaki Y, Kato Y, Sugiyama Y, Kataoka K. J Control Release 2001; 77: 27-38.

[21] Puga AV, Texidor F, Sillanpaa R, Kivekas R, Arca M, Barbera G, Vinas C. Chemistry 2009; 15: 9755-9763.

[22] Jong WHD, Borm PJ. Int J Nanomedicine 2008; 3: 133-149.

[23] Li T, Hamdi J, Hawthorne MF. Bioconjug Chem 2006; 17: 15-20.

[24] Morrison, DE, Issa F, Bhadbhade M, Groebler L, Witting PK, Kassiou M, Rutledge PJ, Rendina LM. J Biol Inorg Chem 2010; 15: 1305-1318. 
Department of Materials Science, University of Tsukuba And International Center for Materials Nanoarchitectonics (MANA),

National Institute for Materials Science

1-1-1 Ten-noudai, Tsukuba 305-8573, Japan

Yukio Nagasaki, Ph. D.

Phone: +81-29-853-5749

Fax: $\quad+81-29-853-5749$

E-mail: nagasaki@nagalabo.jp

January 16, 2012

Prof. David Williams,

Editor-in-Chief

Biomaterials,

Dear Professor David Williams:

Attachment is a copy of our manuscript entitled:

"Pharmacokinetics of Core-Polymerized, Boron-Conjugated Micelles Designed for Boron Neutron Capture Therapy for Cancer.

,

by Shogo Sumitani, Motoi Oishi, Tatsuya Yaguchi, Hiroki Murotani, Yukichi Horiguchi, Minoru Suzuki, Koji Ono, Hironobu Yanagie and myself.

The manuscript has been revised according to the reviewers' comments. You will find here a file of the revised version of our manuscript. A list of the answers to the reviewers' comments is also provided.

We believe this manuscript contains essential and scientifically interesting facts, and meets the critical of the Biomaterials. We hope this revision would be satisfactory for the publication in your Journal as an Article

Thank you in advance for your cooperation.

With best wishes,

Sincerely yours,

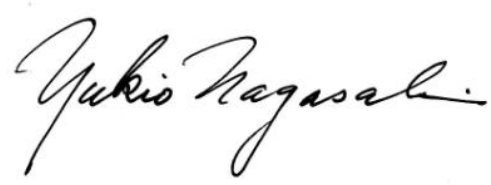

Yukio Nagasaki, Professor 


\section{MANDATORY EDITOR'S REQUIREMENTS}

1. I would like you to make a slight change to the title, giving it more focus.. Please change it to ' Pharmacokinetics of Core-Polymerized, Boron-Conjugated Micelles Designed for Boron Neutron Capture Therapy for Cancer'.

2. You use the word 'novel' in the manuscript. This is not necessary and detracts from the scientific rigour. I would like you to delete the word. The same applies to 'new' and similar words, which should not be substituted for 'novel'

3. In the references you should use the accepted abbreviated form for the journal titles - you are inconsistent with this. These can be found in standard databases such as PubMed.

\section{Answer}

Thank you very much for your comments. According to your comments, we modified the manuscript.

(Revision: the title was changed as follows)

Pharmacokinetics of Core-Polymerized, Boron-Conjugated Micelles Designed for Boron Neutron Capture Therapy for Cancer.

\section{Answer to reviewer 1:}


Thank you very much for your courteous review and kind comments. According to your comments, we revised the manuscript as follows (the red colored sentences were revised or newly added sentences in the new manuscripts):

\section{Comment}

This work is concerned with the synthesis of a new boron compound for BNCT based on delivering a carborane molecule by micelles (nanoparticles) constructed by copolymerization (PM micelles). In another recent article published by some of the authors (Sumitani S, Oishi M, Nagasaki Y. Carborane confined nanoparticles for boron neutron capture therapy: Improved stability, blood circulation time and tumor accumulation. React Funct Polym, 2011;71:684-693), a synthesis of a very similar compound (same technique to produce the micelles) but cross-linking (CL) the carborane instead of integrating the molecule to the micelle by copolymerization was presented. According to their comments in the present manuscript, the CL compound was unable to deliver therapeutic amounts of boron to the tumor according to their estimations (yet, no BNCT irradiation was performed to investigate the degree of tumor control). Then, in the present manuscript, they chose to prepare the carborane co-monomer with only one functional group instead of two as in their previous work with the aim of loading a greater amount of boron to the micelles. For comparison, non-polymerized micelles (NPM) containing also a carborane molecule were used to test the ability of the PM to preserve their boron load without leaking when exposed to serum proteins, concluding that covalent interaction was the cause of the PM stability. In addition, an animal model was used in this opportunity to understand its pharmacokinetics and biodistribution and the degree of tumor control achieved when irradiated with thermal neutrons. It is of great importance for the future of BNCT to have interdisciplinary research groups committed to face sustained efforts in creating new boron compounds and delivery strategies. This work is contributory since it integrates several specialties equally important for obtaining a suitable compound and therefore deserves to be published.

However, there are still some issues that must be considered when proposing a new boron delivery agent and would be of great importance if the authors state them clearly in this work.

The manuscript is clear and well written and does not demand extensive grammatical corrections, perhaps just checking for typing mistakes.

[Q1] The idea of sustained blood circulation is important since it permits the compound to have enough time to traverse the barriers that must be crossed to reach the tumor cells; however, it is also a drawback since normal tissues could be exposed to high boron radiation doses, unless the compound does not leave the normal vasculature and enters the interstitium. The authors should comment on this, perhaps anticipating the need for further investigations in terms of boron accumulation in normal tissues that must be protected, e.g., the organs at risk in the future treatment.

\section{Answer}

Thank you for your comment. We understand the importance of the risk at normal organs after the irradiation. 

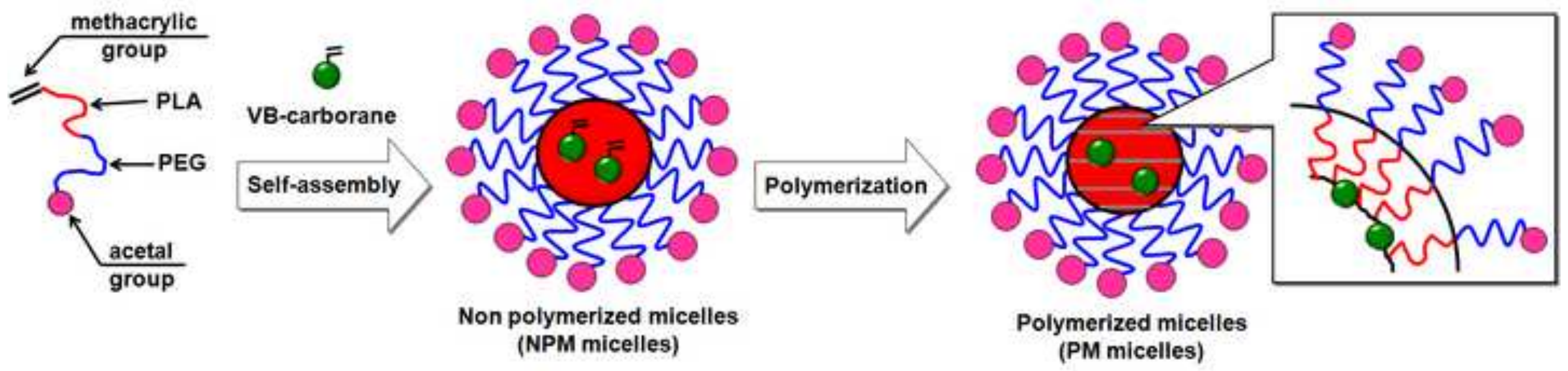

Polymerized micelles (PM micelles) 


\section{Figure}

Click here to download high resolution image

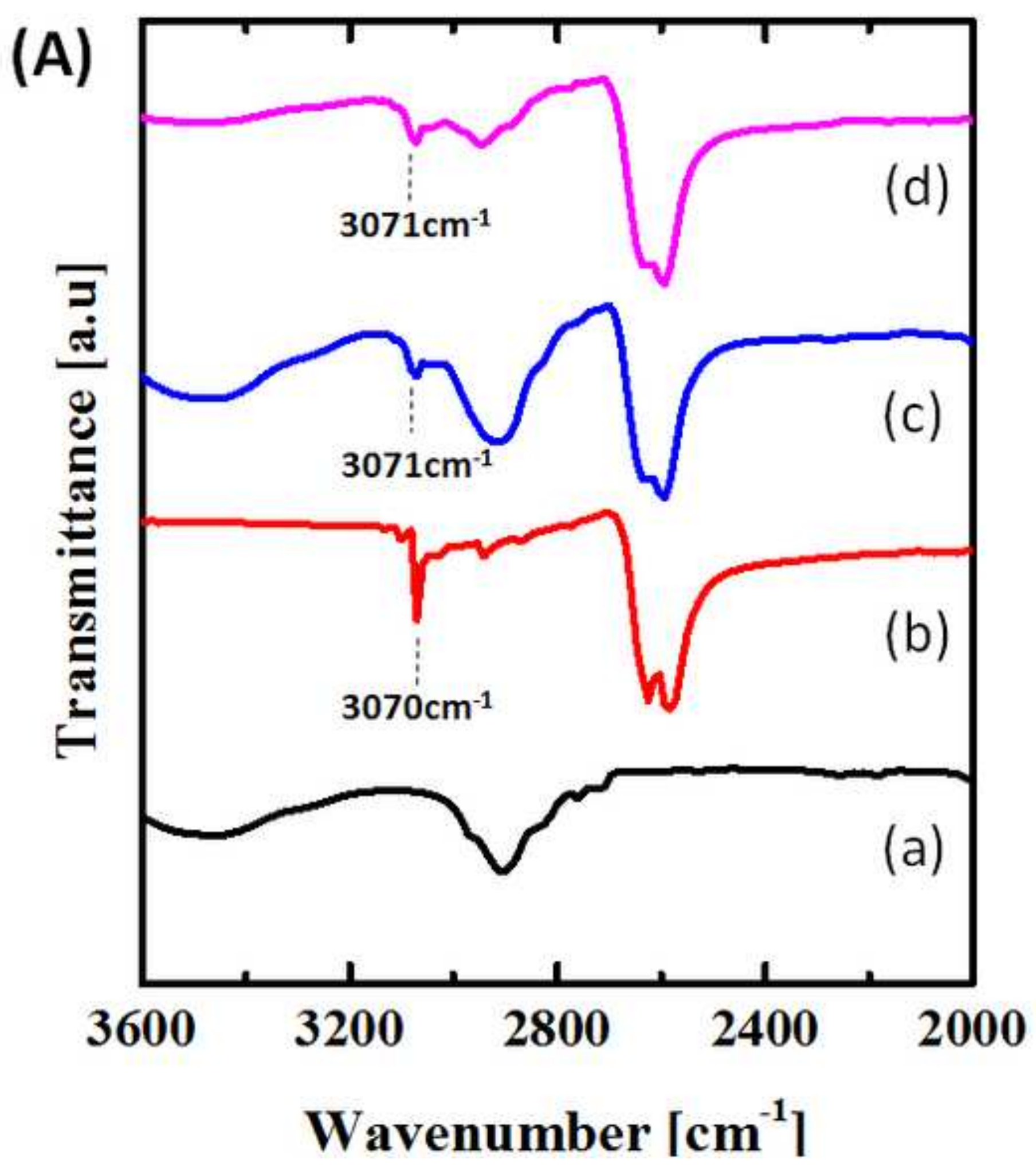




\section{Figure}

Click here to download high resolution image

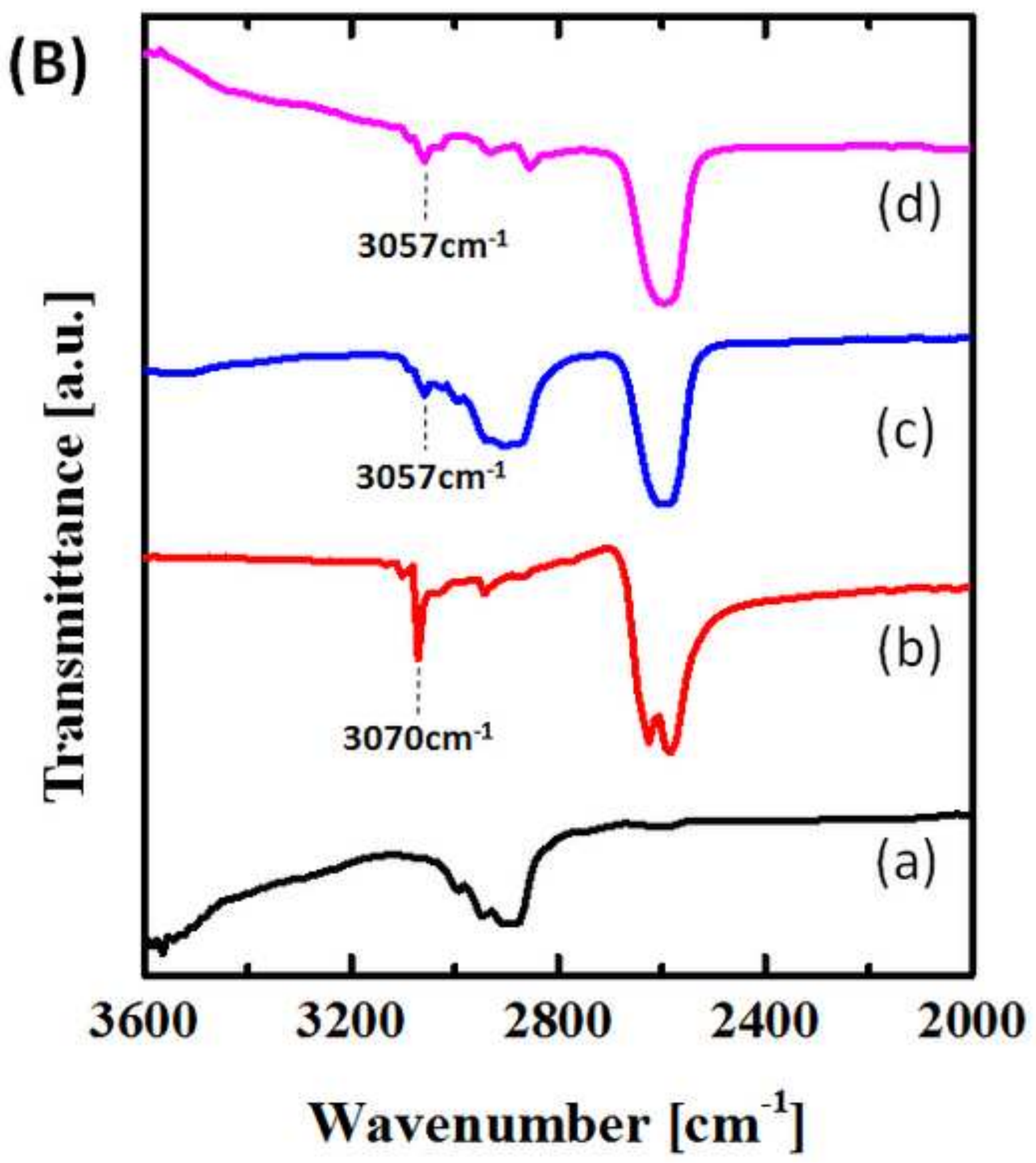


Figure
Click here to download high resolution image

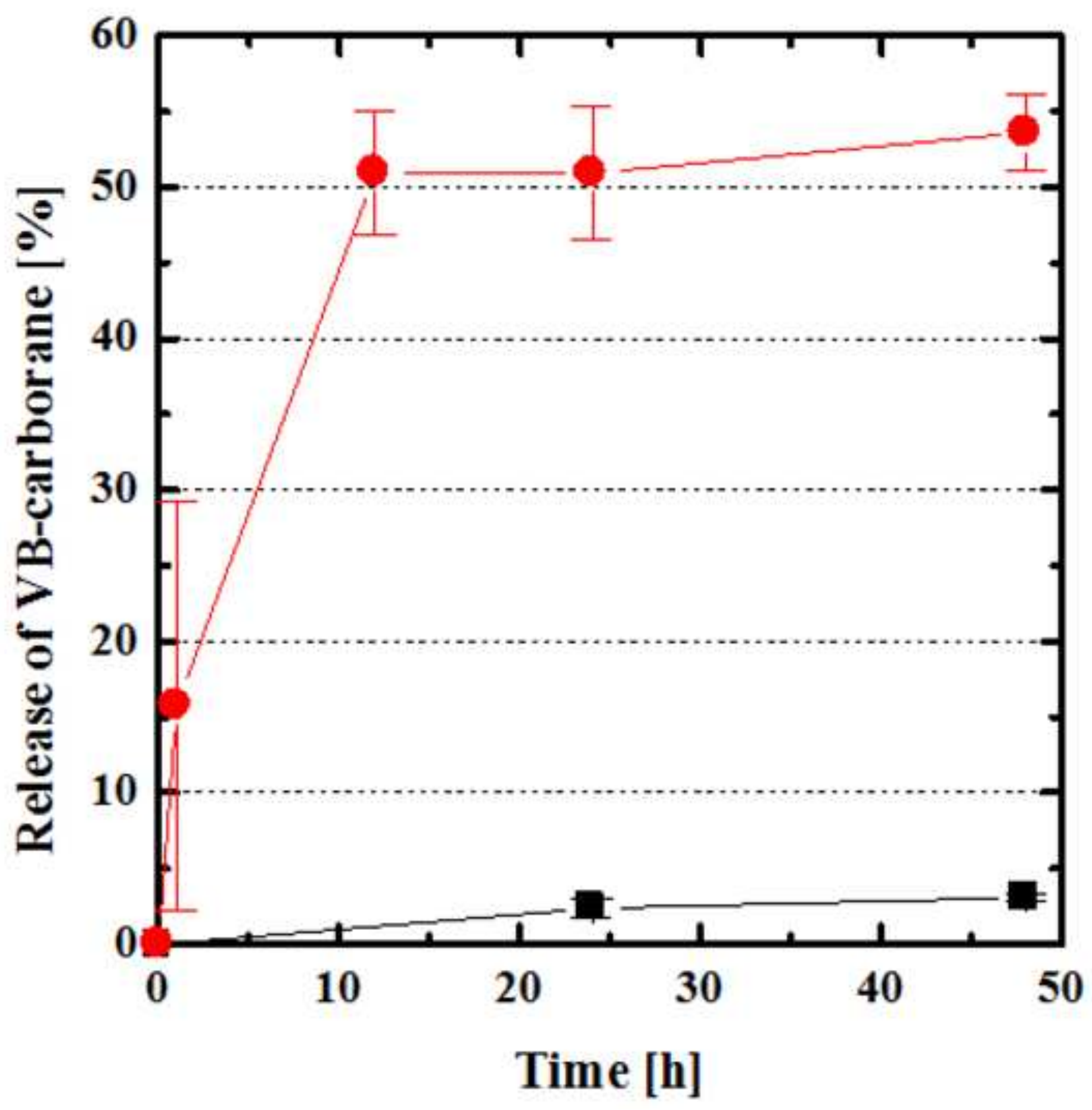


Click here to download high resolution image

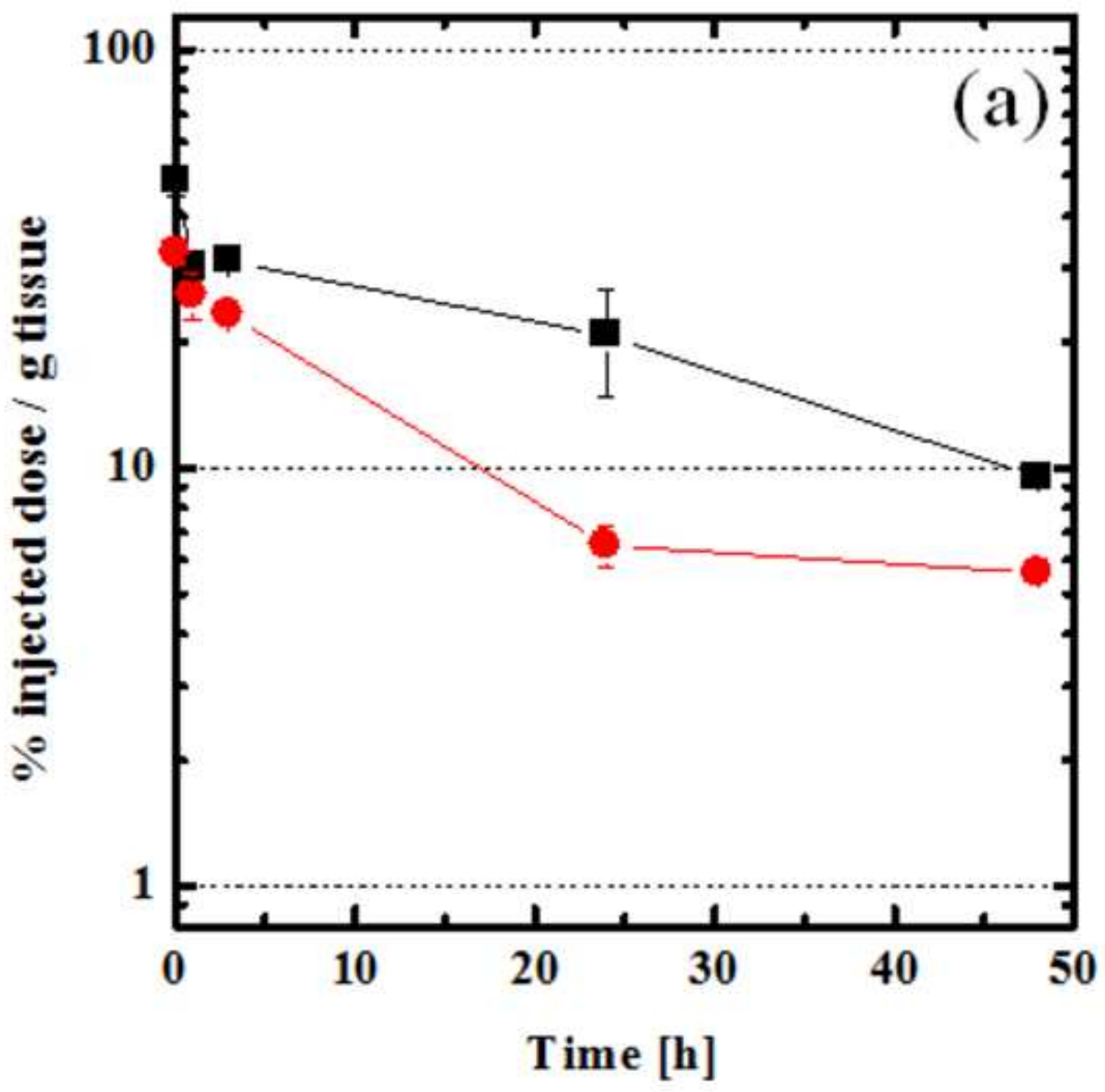


Figure
Click here to download high resolution image

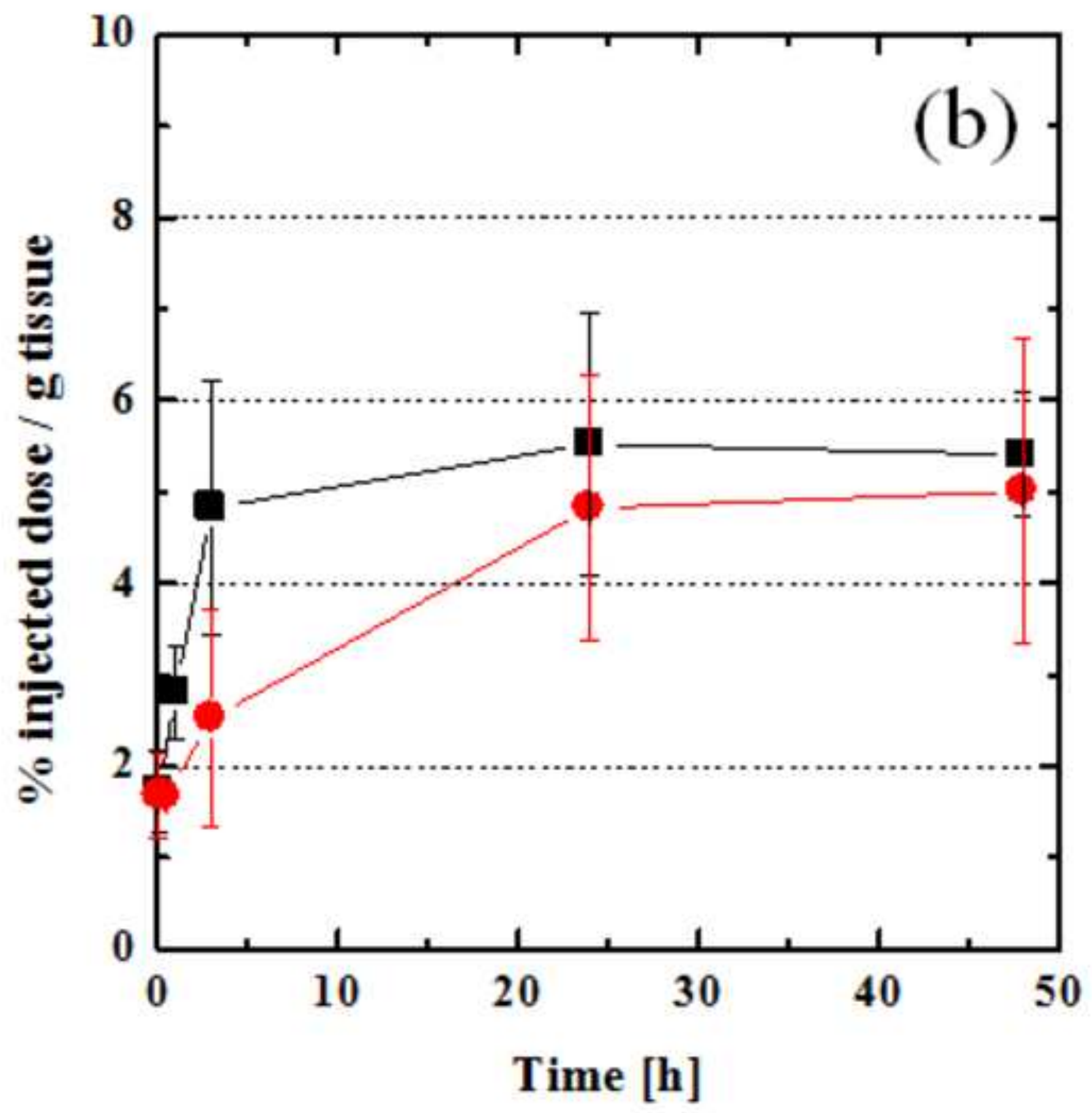


Click here to download high resolution image

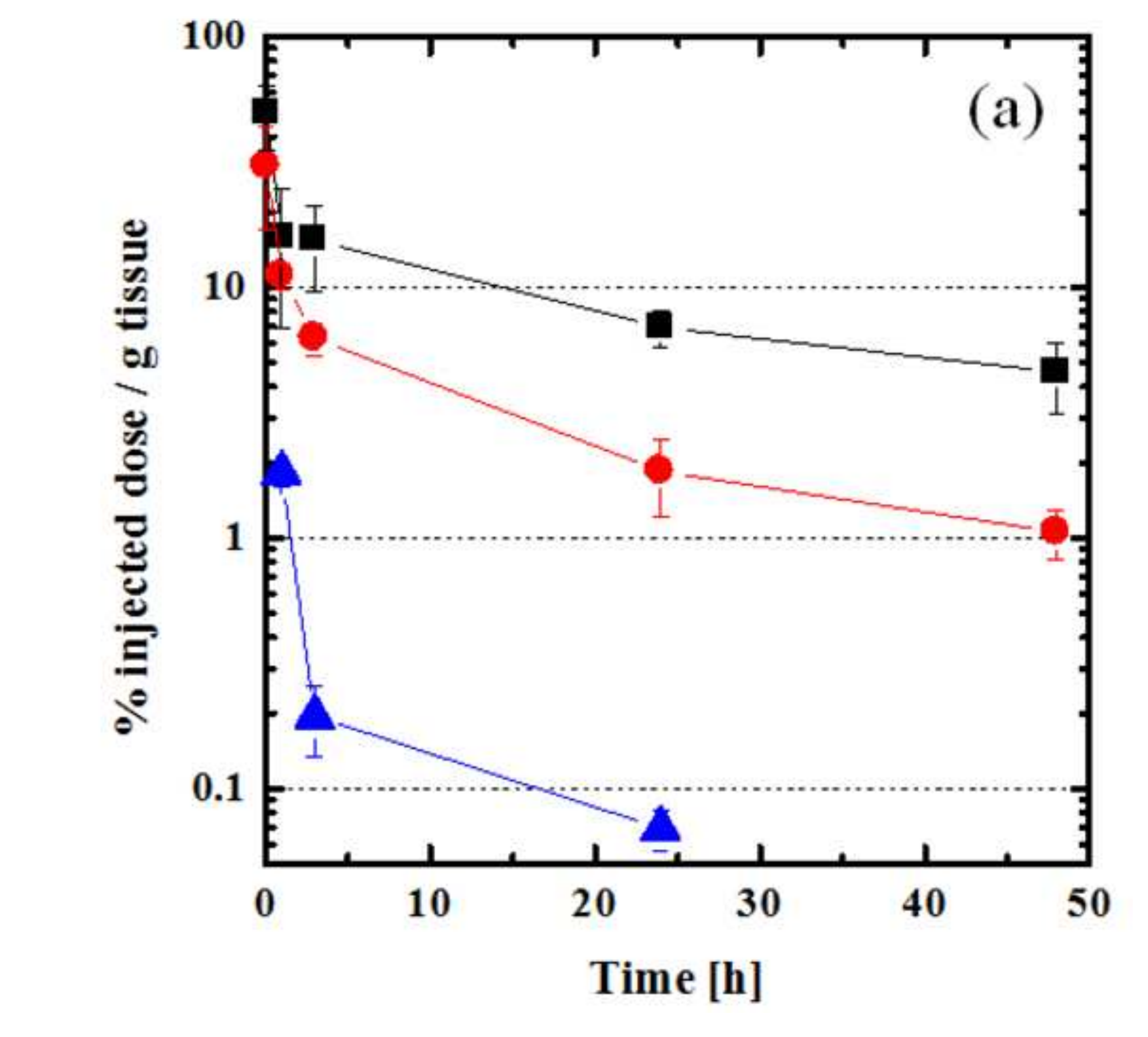


Click here to download high resolution image

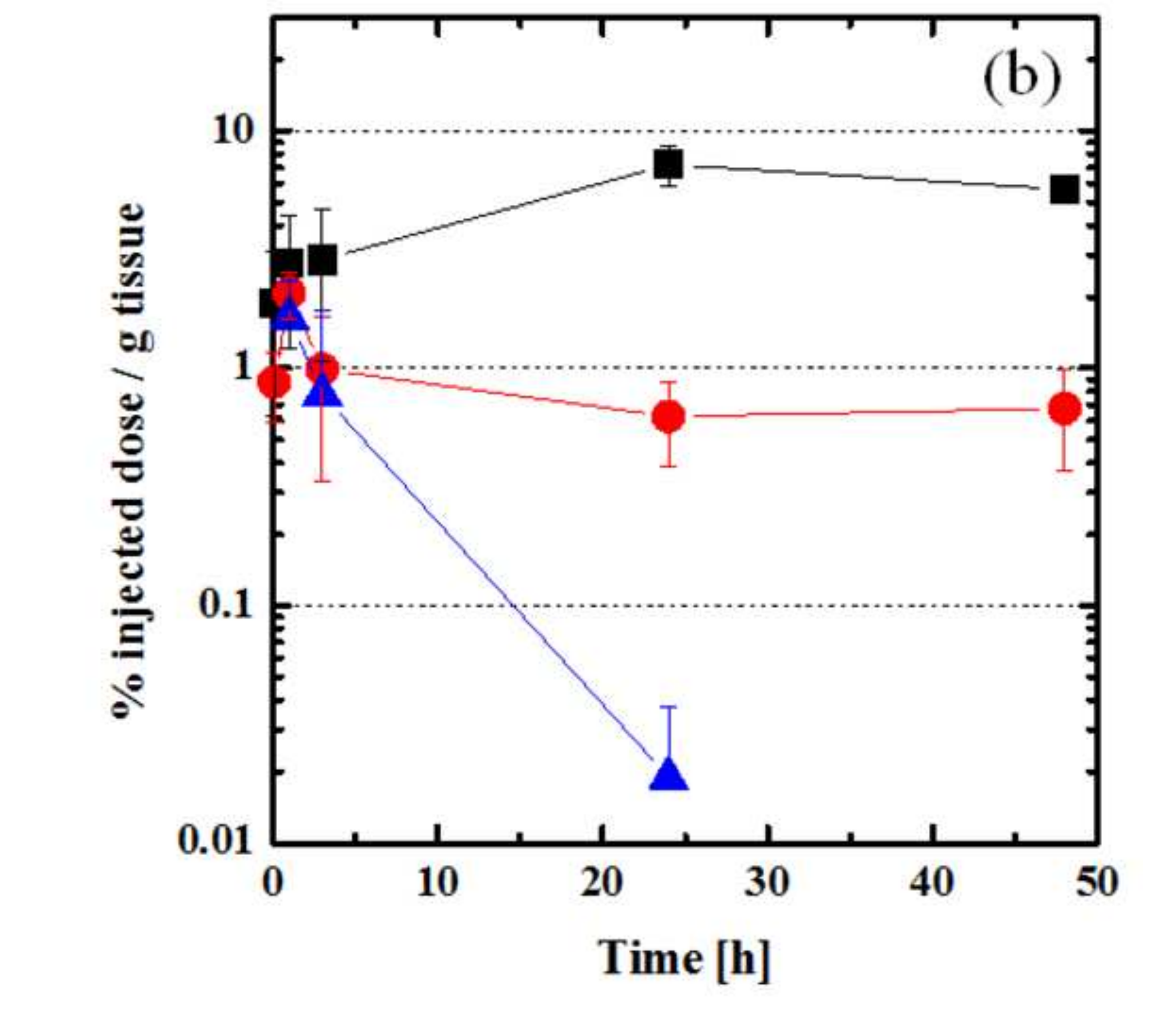

Click here to download high

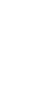


Click here to download high resolution image

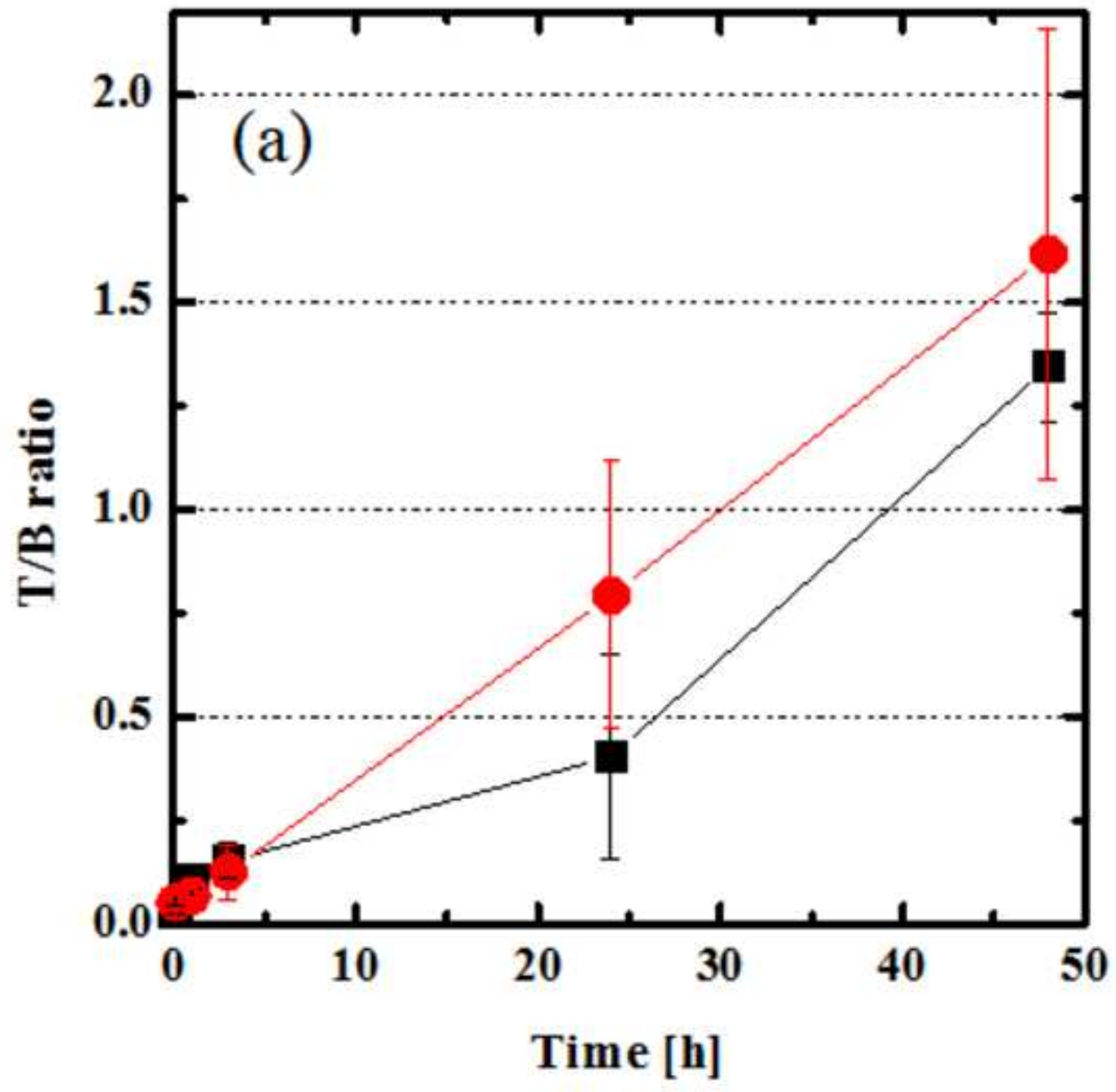


Figure
Click here to download high resolution image

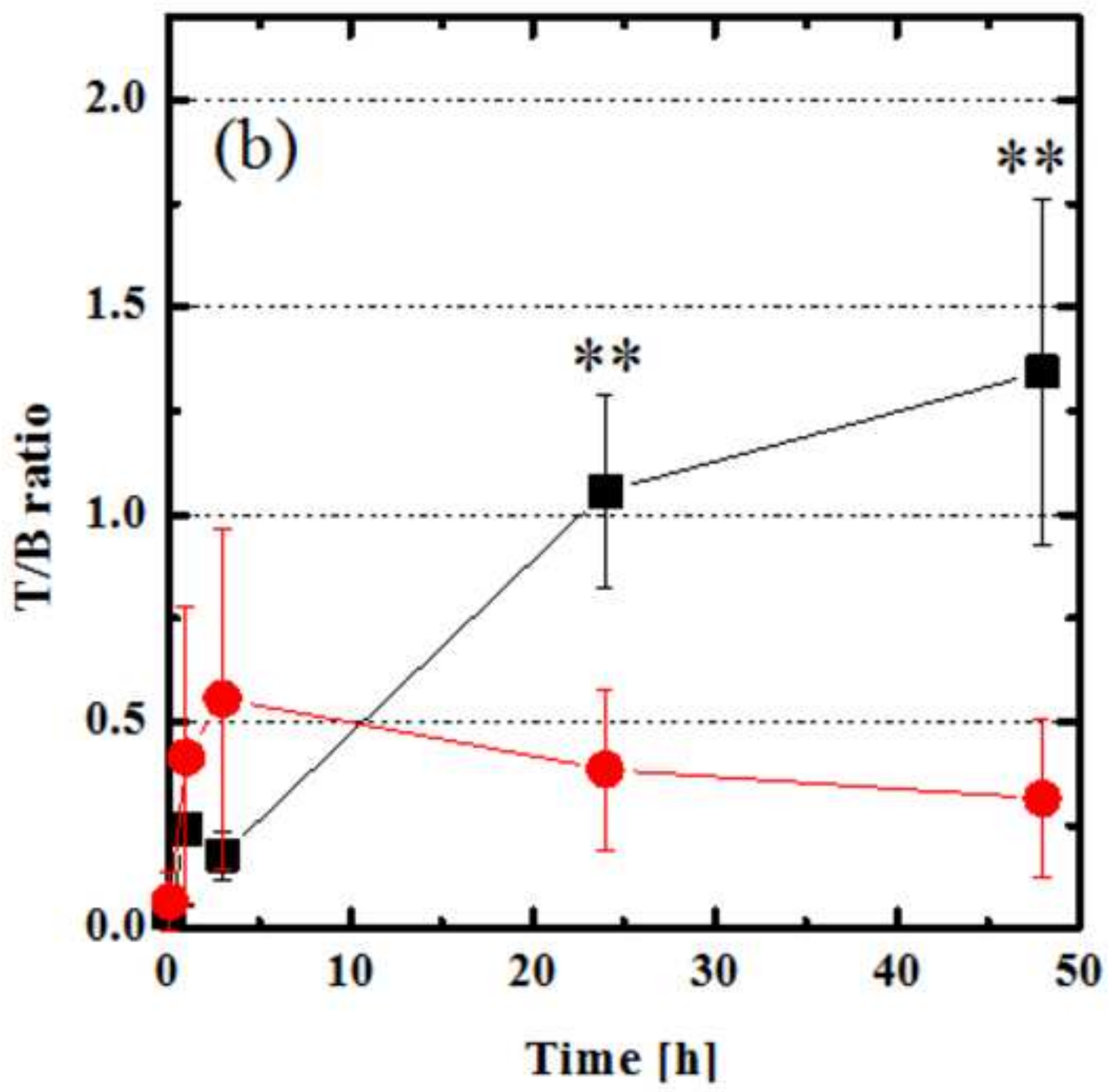


Click here to download high resolution image

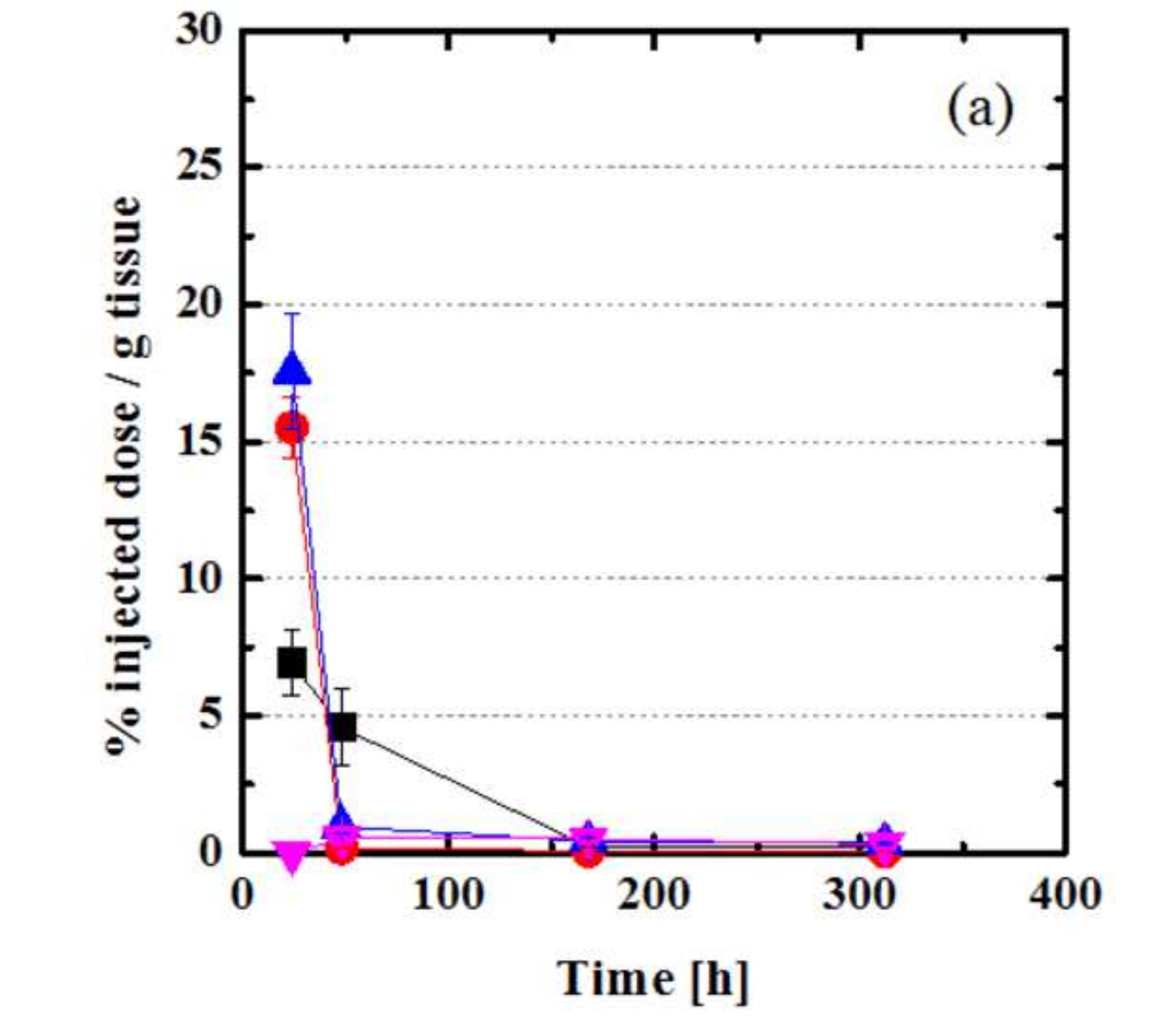

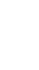


Figure
Click here to download high resolution image

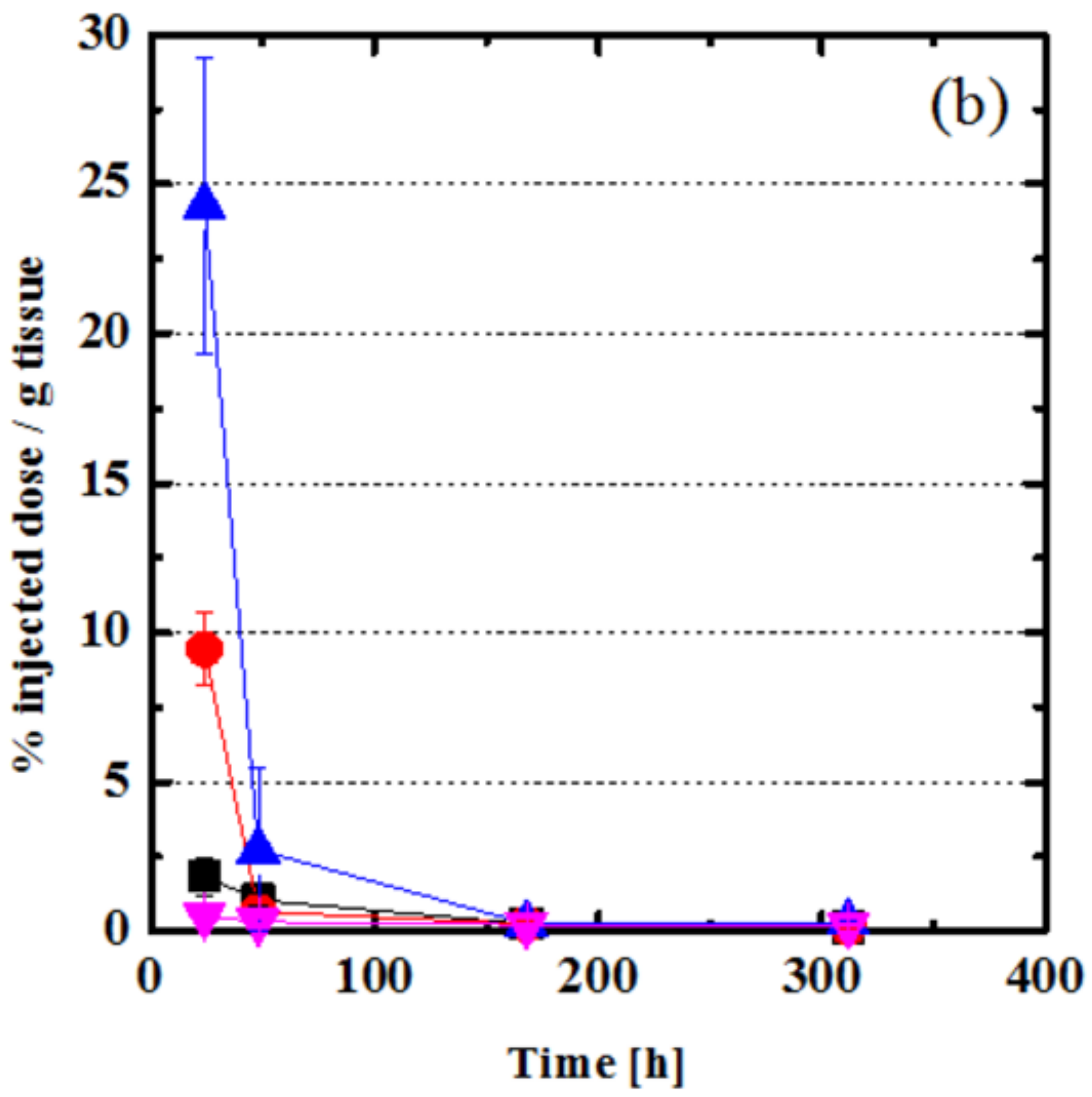




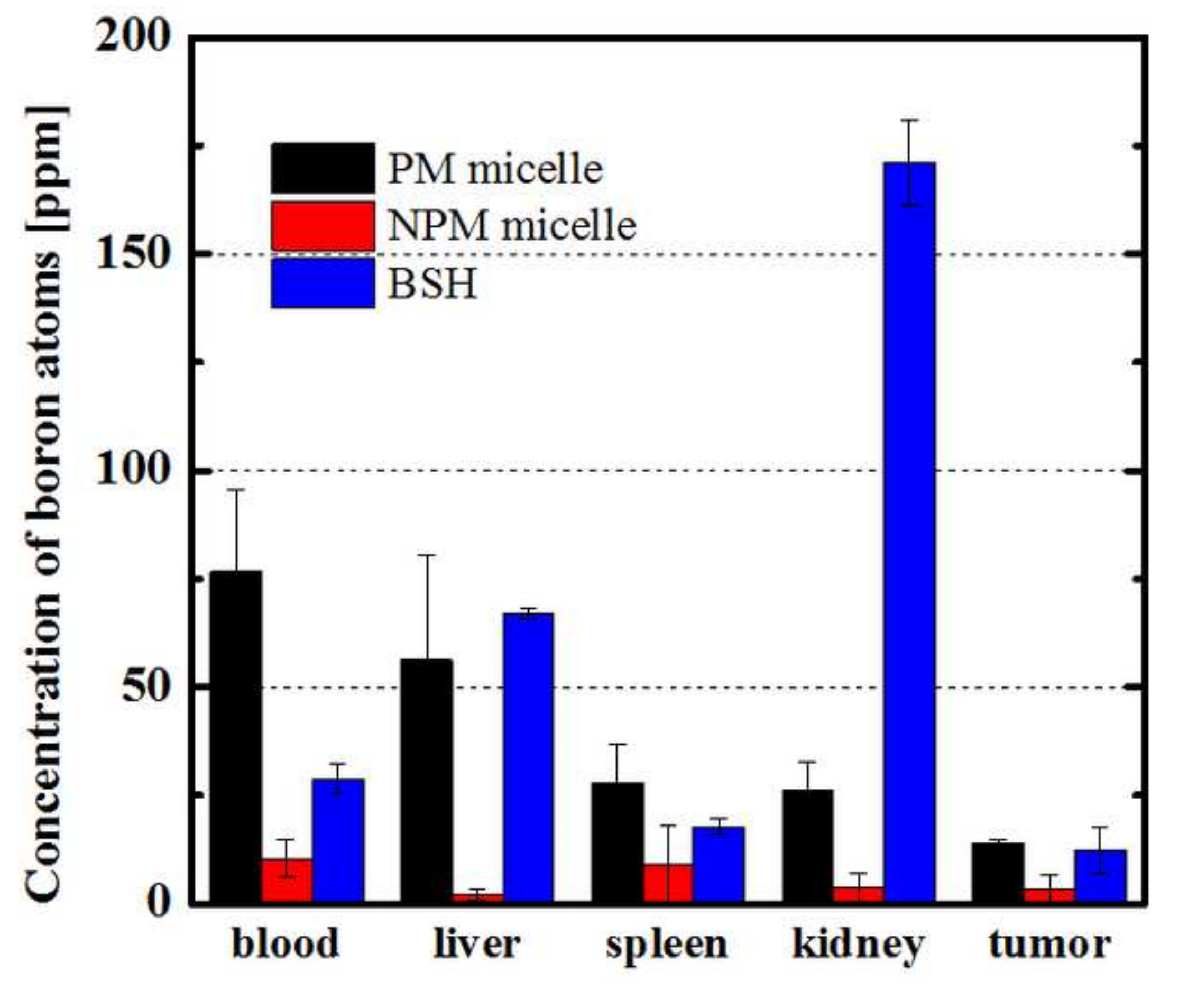

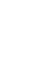




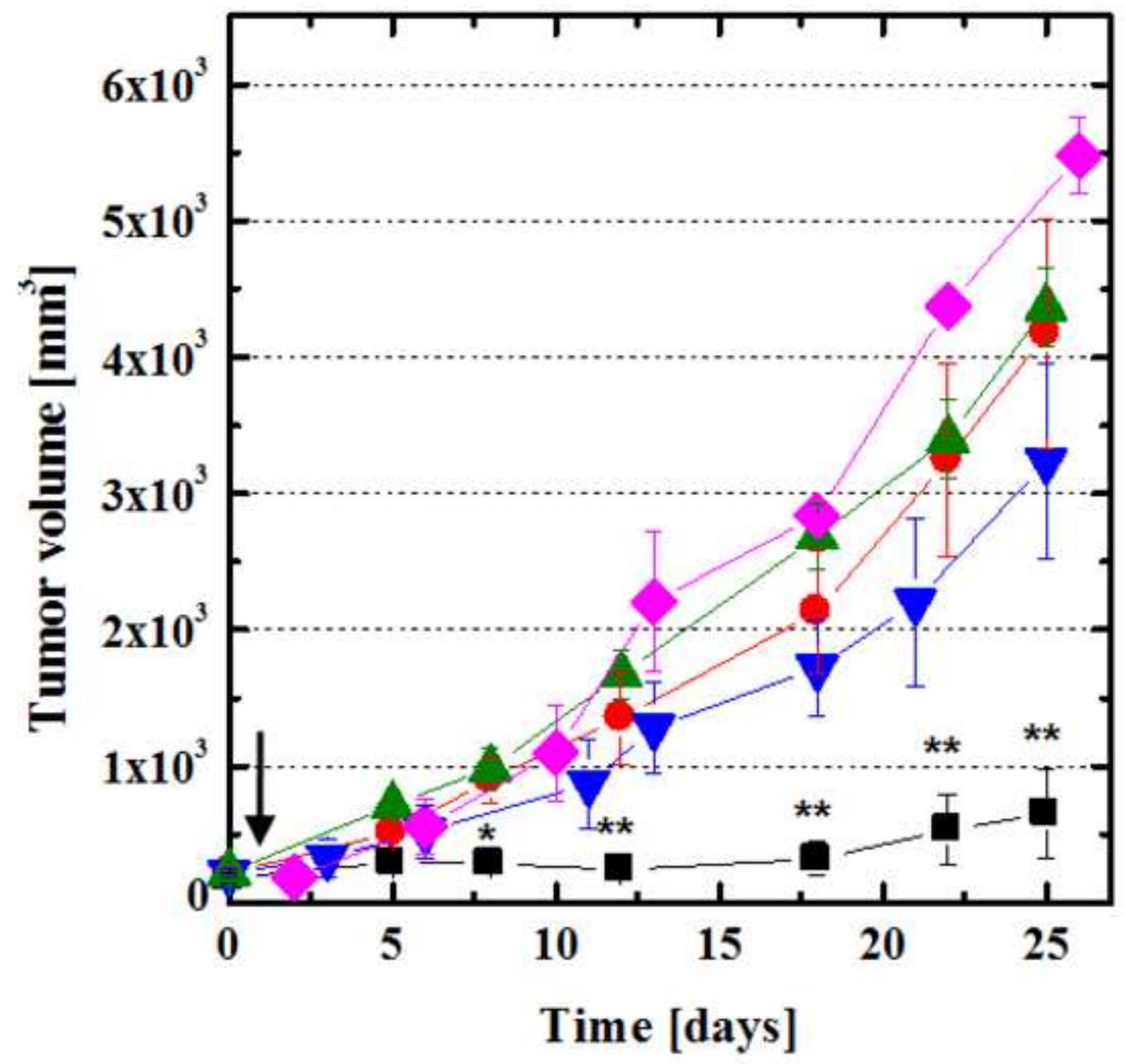




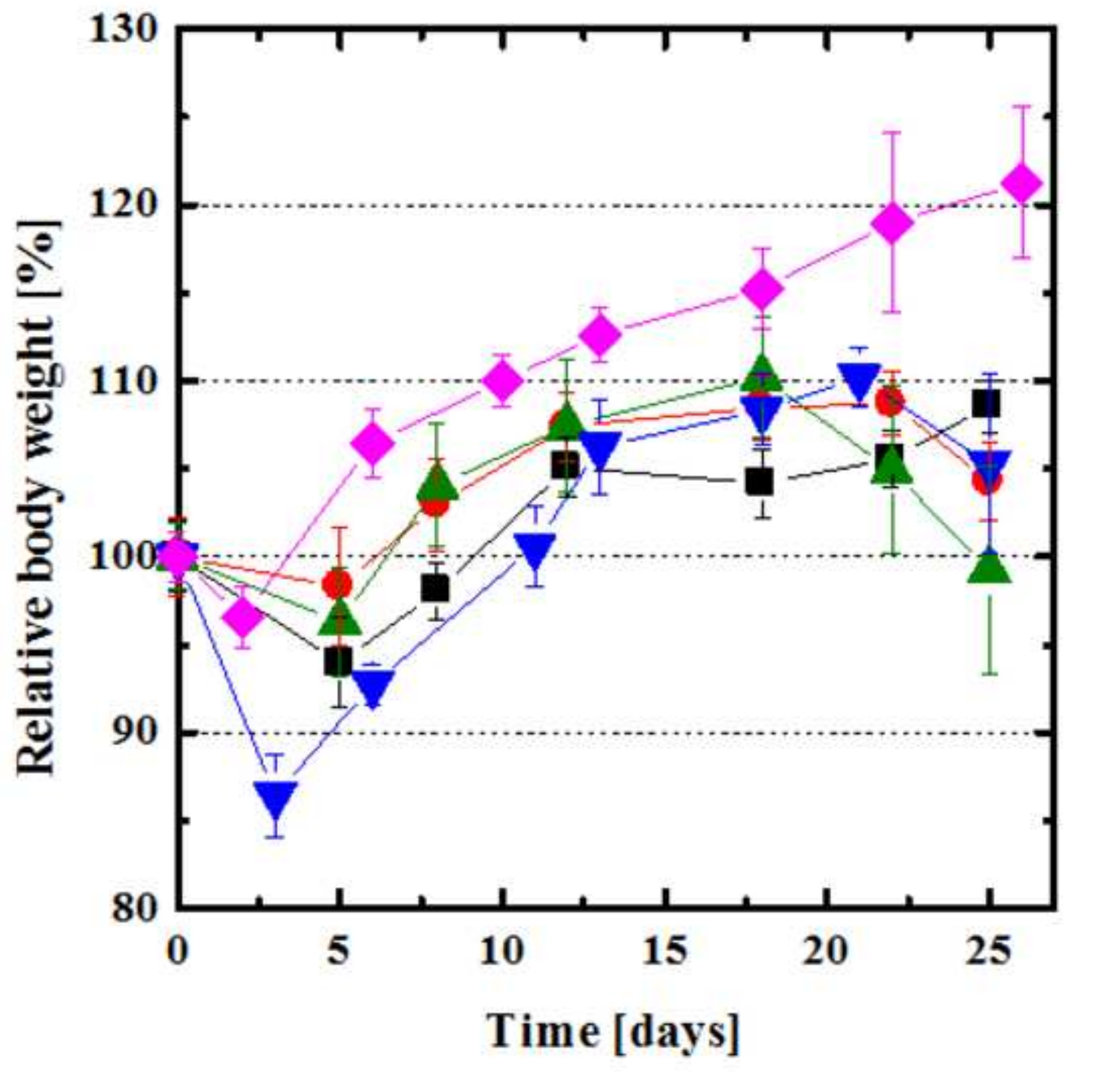

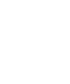




\section{Supplementary data}

\section{Pharmacokinetics of Core-Polymerized, Boron-Conjugated Micelles Designed for Boron Neutron Capture Therapy for Cancer}

Shogo Sumitani ${ }^{\text {a }}$, Motoi Oishi ${ }^{\text {a }}$, Tatsuya Yaguchi ${ }^{\text {a }}$, Hiroki Murotani ${ }^{\text {a }}$, Yukichi Horiguchi ${ }^{\text {a }}$, Minoru Suzuki ${ }^{\mathrm{d}}$, Koji Ono ${ }^{\mathrm{d}}$, Hironobu Yanagie ${ }^{\mathrm{e}}$, Yukio Nagasaki ${ }^{\mathrm{a}, \mathrm{b}, \mathrm{c}^{*}}$

*Corresponding author. Tel: (+81)-29-853-5749, Fax.: (+81)-29-853-5749, e-mail address: yukio@nagalabo.jp

a. Department of Materials Science, Graduate School of Pure and Applied Sciences, University of Tsukuba, Tennoudai 1-1-1, Tsukuba, Ibaraki 305-8573, Japan

b. Master's School of Medical Sciences, Graduate School of Comprehensive Human Sciences, University of Tsukuba, Tennoudai 1-1-1, Tsukuba, Ibaraki 305-8573, Japan

c. Satellite Laboratory, International Center for Materials Nanoarchitectonics (WPI-MANA), National Institute of Materials Science (NIMS), Tennoudai 1-1-1, Tsukuba, Ibaraki 305-8573, Japan

d. Radiation Oncology Research Laboratory, Research Reactor Institute, Kyoto University, Osaka, 2 Asahiro nishi, Kumatori, Sennan, Osaka 590-0494, Japan

e. Department of Nuclear Engineering and Management, School of Engineering, University of Tokyo, 7-3-1 Hongo Bunkyo, Tokyo 113-8655, Japan

\section{Materials}

Tetrahydrofuran (THF; Kanto Chemicals Co. Ltd., Tokyo, Japan) was dried over lithium aluminum hydride and distilled under nitrogen atmosphere. 3,3-Diethoxy-1-propanol (Aldrich Chemical Co. Ltd., Milwaukee, WI) was dried over sodium and distilled under reduced pressure. Ethylene oxide (EO; Sumitomo Seika Chemicals Co. Ltd., Hyogo, Japan) was purified by distillation over $\mathrm{CaH}_{2}$. D,L-lactide (LA, Wako Pure Chemical Industries, Ltd., Osaka, Japan) was purified by sublimation under reduced pressure after recrystallization twice from ethyl acetate. Potassium naphthalene was prepared according to a conventional method and the concentration was determined by titration. $o$-Carborane (Wako Pure Chemical Industries), ${ }^{10} \mathrm{~B}$-enriched $o$-carborane (Katchem spol. s.r.o., Ltd., Prague, Czech) and butyllithium (BuLi; $1.6 \mathrm{M}$ in $n$-hexane, Kanto Chemicals) were used as received. 4-Vinylbenzyl chloride (kindly provided by Seimi Chemical Co., Tokyo, Japan) was purified by passed through silica gel column and distilled under reduced pressure. High-resolution mass spectrometry using electrospray ionization mass spectrometry (HRMS (ESI+)) was conducted for the synthesized monomers on an Applied Biosystems QStar/Pulsar i.

\section{Synthesis of acetal-PEG- $b$-PLA-MA block copolymer (Scheme S1)}

3,3-Diethoxy-1-propanol ( $79 \mu \mathrm{L}, 0.5 \mathrm{mmol})$ and THF $(15 \mathrm{~mL})$ were added to a round bottom flask equipped with a three-way stop-cock under nitrogen atmosphere. To this solution, potassium naphthalene solution $(0.42 \mathrm{~mol} / \mathrm{L}$ in THF, $1.2 \mathrm{~mL})$ was added, and the reaction mixture was stirred for $30 \mathrm{~min}$ at room temperature to obtain of potassium alcholate as an initiator. The condensed EO $(3.4 \mathrm{~mL}, 68.1 \mathrm{mmol})$ was added to the initiator solution via a cooled syringe, and the reaction 
mixture was stirred for 2 days at room temperature. Aliquots of the reaction mixture were sampled for SEC measurement to determine the molecular weight of PEG. SEC measurement was carried out on an HLC-8020 system (Tosoh, Tokyo, Japan) equipped with an internal refractive index detector and a combination of TSKgel G4000 ${ }_{\mathrm{HR}}$ and TSKgel G3000 ${ }_{\mathrm{HR}}$ columns (Tosoh, Tokyo, Japan), using THF as an eluent (Figure S1). The molecular weight $\left(M_{\mathrm{n}}\right)$ and molecular weight distribution $\left(M_{\mathrm{w}} / M_{\mathrm{n}}\right)$ of PEG were 5,600 and 1.02, respectively, as determined by SEC measurements based on the PEG calibration. After the polymerization of EO, a solution of D,L-lactide in THF (17.3 mmol, $21.6 \mathrm{~mL}, 0.8 \mathrm{M})$ was added, and the reaction mixture was further stirred for $2 \mathrm{~h}$ at room temperature. Methacrylic anhydride $(1.6 \mathrm{~mL}, 10 \mathrm{mmol})$ was added to the reaction mixture to terminate the reaction and introduce the methacryloyl moiety to the living polymer chain end. The reaction mixture was poured into cold 2-propanol $(900 \mathrm{~mL})$, followed by the centrifuging for $15 \mathrm{~min}$ at $5000 \mathrm{rpm}$ at $-4{ }^{\circ} \mathrm{C}$. The recovered polymer was finally freeze-dried with benzene to obtain the acetal-PEG- $b$-PLA-MA polymer as a white powder (acetal-PEG- $b$-PLA-MA: $85.7 \%$ yield). A ${ }^{1} \mathrm{H}-\mathrm{NMR}$ spectrum of acetal-PEG- $b$-PLA-MA is shown in Figure S2 with assignments, where the peaks of terminal methacryloyl moiety were observed at $\delta 5.6$ and $6.2 \mathrm{ppm}$ along with the peaks of acetal moiety were observed at $\delta 4.6 \mathrm{ppm}$. The segment length of PLA was estimated from the ${ }^{1} \mathrm{H}-\mathrm{NMR}$ spectrum based on the peak integral ratio of the methylene protons of PEG $\left(\mathrm{OCH}_{2} \mathrm{CH}_{2}: \delta 3.5 \mathrm{ppm}\right)$ and the methine proton of the PLA unit $\left(\mathrm{COCH}\left(\mathrm{CH}_{3}\right): \delta 5.2 \mathrm{ppm}\right)$, assuming the $M_{\mathrm{n}}$ of PEG 5,600. The $M_{\mathrm{n}}$ of PLA segment was 5,100. The functionality of methacryloyl and acetal moiety was determined to be 90 and $99 \%$, respectively, as determined by the ${ }^{1} \mathrm{H}-\mathrm{NMR}$ spectroscopy. SEC $M_{\mathrm{n}}=10,500, M_{\mathrm{w}} / M_{\mathrm{n}}=1.07 ;{ }^{1} \mathrm{H}-\mathrm{NMR}(270 \mathrm{MHz}$, $\left.\mathrm{CDCl}_{3}\right): \delta(\mathrm{ppm}) 1.18\left(\mathrm{t}, J=7.0 \mathrm{~Hz}, 6 \mathrm{H}, \mathrm{CH}_{3} \mathrm{CH}_{2} \mathrm{O}-\right), 1.57\left(\mathrm{~m}, 213 \mathrm{H},-\mathrm{COCH}\left(\mathrm{CH}_{3}\right)-\right), 1.73(\mathrm{br}, 2 \mathrm{H}$, acetal- $\left.\mathrm{CHCH}_{2} \mathrm{CH}_{2} \mathrm{O}-\right) 1.76\left(\mathrm{br},-\mathrm{C}\left(\mathrm{CH}_{3}\right)=\mathrm{CH}_{2}\right), 3.69(\mathrm{~m}, 509 \mathrm{H}$, PEG backbone), $4.64(\mathrm{t}, J=5.8 \mathrm{~Hz}$, $1 \mathrm{H}$, acetal- $\left.\mathrm{CHCH}_{2^{-}}\right), 5.15\left(\mathrm{~m}, 71 \mathrm{H}, \mathrm{COCH}\left(\mathrm{CH}_{3}\right)\right), 5.61\left(\mathrm{~d}, J=1.3 \mathrm{~Hz} 1 \mathrm{H},-\mathrm{C}\left(\mathrm{CH}_{3}\right)=\mathrm{CH}_{2}\right), 6.20(\mathrm{~d}$, $\left.J=1.1 \mathrm{~Hz}, 1 \mathrm{H},-\mathrm{C}\left(\mathrm{CH}_{3}\right)=\mathrm{CH}_{2}\right)$.

Synthesis of natural abundance of 1-(4-vinylbenzyl)-closo-carborane (VB-carborane) (Scheme S2)

$o$-Carborane $(0.38 \mathrm{~g}, 2.6 \mathrm{mmol})$ dissolved in THF $(20 \mathrm{~mL})$ was introduced in a round bottom flask equipped with a three-way stop-cock under nitrogen atmosphere, and the flask was cooled to $0{ }^{\circ} \mathrm{C}$. To this solution, BuLi (1.6 M in hexane) was added dropwise (1.6 mL, $2.6 \mathrm{mmol})$, and the reaction mixture was stirred for $30 \mathrm{~min}$ at $0{ }^{\circ} \mathrm{C}$. The reaction mixture was allowed to warm to room temperature, and 4-vinylbenzyl chloride $(0.38 \mathrm{~mL}, 2.6 \mathrm{mmol})$ was added dropwise. The reaction mixture was further stirred for $8 \mathrm{~h}$ at room temperature, and the proceeding of the reaction was monitored by TLC analysis using straight hexanes $\left(\mathrm{R}_{\mathrm{f}}=0.21\right)$. The solvent was subsequently removed by rotary evaporation, and the crude product was purified by silica gel column in straight hexane to yield the VB-carborane as a white solid $(0.13 \mathrm{~g}$, yields; $19.2 \%) .{ }^{1} \mathrm{H} \mathrm{NMR}(270 \mathrm{MHz}$, $\mathrm{CDCl}_{3}$ ) (Figure S3): $\delta(\mathrm{ppm})$ 1.4-3.5 (br, $11 \mathrm{H}$, carborane), $3.51\left(\mathrm{~s}, 2 \mathrm{H},-\mathrm{CH} \boldsymbol{H}_{2} \mathrm{C}(\mathrm{BH})_{10}\right), 5.30(\mathrm{dd}, J=$ 0.8 and $\left.10.8 \mathrm{~Hz}, 1 \mathrm{H}, \mathrm{CH}_{2}=\mathrm{CHPh}\right), 5.78\left(\mathrm{dd}, J=0.8\right.$ and $\left.17.6 \mathrm{~Hz}, 1 \mathrm{H}, \mathrm{CH}_{2}=\mathrm{CHPh}\right), 6.74(\mathrm{dd}, J=$ 10.8 and $\left.17.6 \mathrm{~Hz}, 1 \mathrm{H}, \mathrm{CH}_{2}=\mathrm{CHPh}\right), 7.10(\mathrm{~d}, J=8.2 \mathrm{~Hz}, 2 \mathrm{H}, \mathrm{Ph}), 7.39(\mathrm{~d}, J=8.2 \mathrm{~Hz}, 2 \mathrm{H}, \mathrm{Ph})$. Elemental Analysis: Calcd. C $50.7 \%$, H $7.74 \%$. Found C $50.8 \%$, H 7.70 \%. ICP-AES: B Calcd. $41.5 \%$, Found $41.4 \%$. MS $\left(\mathrm{ESI}^{+}\right): \mathrm{m} / z$ calcd for $\mathrm{C}_{11} \mathrm{H}_{20} \mathrm{~B}_{10}\left[\mathrm{M}^{+}\right]: 260.2568$; found: 260.2571 .

\section{Synthesis of ${ }^{10} \mathrm{~B}$-enriched VB-carborane}

\footnotetext{
${ }^{10} \mathrm{~B}$-enriched $o$-carborane $(0.10 \mathrm{~g}, 0.69 \mathrm{mmol})$ dissolved in $\mathrm{THF}(5.3 \mathrm{~mL})$ was introduced in a round bottom flask equipped with a three-way stop-cock under nitrogen atmosphere, and the flask was cooled to $0{ }^{\circ} \mathrm{C}$. To this solution, BuLi (1.6 M in hexane) was added dropwise $(0.42 \mathrm{~mL}, 0.69$
} 
mmol), and the reaction mixture was stirred for $30 \mathrm{~min}$ at $0{ }^{\circ} \mathrm{C}$. The reaction mixture was allowed to warm to room temperature, and 4-vinylbenzyl chloride $(0.11 \mathrm{~mL}, 0.69 \mathrm{mmol})$ was added dropwise. The reaction mixture was further stirred for $8 \mathrm{~h}$ at room temperature, and the proceeding of the reaction was monitored by TLC analysis using straight hexanes $\left(R_{f}=0.21\right)$. The solvent was subsequently removed by rotary evaporation, and the crude product was purified by silica gel column in straight hexane to yield the ${ }^{10} \mathrm{~B}$-enriched VB-carborane as a white solid (65 mg, yields; $37.4 \%)$. ${ }^{1} \mathrm{H}$ NMR $\left(270 \mathrm{MHz}, \mathrm{CDCl}_{3}\right): \delta(\mathrm{ppm}) 1.4-3.5$ (br, $11 \mathrm{H}$, carborane), 3.51 (s, 2H, $\left.-\mathrm{CH}_{2} \mathrm{C}(\mathrm{BH})_{10}\right), 5.30\left(\mathrm{dd}, J=0.8\right.$ and $\left.10.8 \mathrm{~Hz}, 1 \mathrm{H}, \mathrm{CH}_{2}=\mathrm{CHPh}\right), 5.78(\mathrm{dd}, J=0.8$ and $17.6 \mathrm{~Hz}, 1 \mathrm{H}$, $\mathrm{CH}_{2}=\mathrm{CHPh}$ ), $6.70\left(\mathrm{dd}, J=10.8\right.$ and $\left.17.6 \mathrm{~Hz}, 1 \mathrm{H}, \mathrm{CH}_{2}=\mathrm{CHPh}\right), 7.10(\mathrm{~d}, J=8.2 \mathrm{~Hz}, 2 \mathrm{H}, \mathrm{Ph}), 7.39(\mathrm{~d}$ $J=8.2 \mathrm{~Hz}, 2 \mathrm{H}, \mathrm{Ph}$ ). Elemental Analysis: Calcd. C $52.4 \%, \mathrm{H} 7.93 \%$. Found C $53.2 \%, \mathrm{H} 7.63 \%$. ICP-AES: B Calcd. $39.7 \%$, Found $40.1 \%$.

\section{Cell culture}

Colon-26 cells derived from mouse colorectal carcinoma cell line were obtained from RIKEN BioResource Center. The cells were grown in Dulbecco's modified Eagle's medium (DMEM) that was supplemented with $10 \% \mathrm{FBS}, 100$ units $\mathrm{mL}^{-1}$ penicillin, and $100 \mu \mathrm{g} \mathrm{mL}^{-1}$ streptomycin at $37^{\circ} \mathrm{C}$ in a humidified $5 \% \mathrm{CO}_{2}$ atmosphere.

\section{In vitro cytotoxicity}

The colon-26 cells were seeded onto 96-well plate at a seeding density of $10^{4}$ cells/well and incubated for $24 \mathrm{~h}$ in $100 \mu \mathrm{L}$ DMEM containing $10 \% \mathrm{FBS}, 100$ units $/ \mathrm{mL}$ penicillin and $100 \mu \mathrm{g} / \mathrm{mL}$ streptomycin at $37{ }^{\circ} \mathrm{C}$ in humidified $5 \% \mathrm{CO}_{2}$ atmosphere. Then, the culture medium of each well was replaced with $90 \mu \mathrm{L}$ of fresh medium, followed by the addition of $10 \mu \mathrm{L}$ sample solutions containing various concentration of NPM micelles, PM micelles, or VB-carborane dissolved in DMSO. After incubation for $24 \mathrm{~h}$, the metabolic activity of each well was evaluated by WST- 8 assay (Cell Counting Kit-8, Dojindo, Japan) The optical absorbance was measured at $450 \mathrm{~nm}$, using an ARVO MX (PerkinElmer, Waltham, MA) and converted to the percentage (cell viability) relative to that for mock cells (buffer-treated cells).

\section{Conjugation of tyrosine residues with PM and NPM micelles}

To clarify the biodistribution of the micelles, the preparation of ${ }^{125} \mathrm{I}$ (radioisotope)-labeled NPM and PM micelles were performed. A tyrosine residue (Tyr), as a site of radiolabeling, was introduced onto the NPM or PM micelles. An aqueous solution of NPM or PM micelles bearing acetal groups $(10.0 \mathrm{~mL}, 2.0 \mathrm{mg} / \mathrm{mL})$ was adjusted to $\mathrm{pH} 2$ using $1.0 \mathrm{M}$ hydrochloric acid, and the resulting solution was stirred for $2 \mathrm{~h}$ at room temperature to prepare NPM or PM micelles with aldehyde groups. Purification was performed with dialysis against a large quantity of water $(2.0 \mathrm{~L})$ using a pre-swollen semi-permeable membrane (MWCO. 12,000-14,000) for $24 \mathrm{~h}$. The dialysate water was exchanged at 2, 5 and $8 \mathrm{~h}$ after the beginning of dialysis. To a solution of the NPM or PM micelles bearing aldehyde groups $(10.0 \mathrm{~mL}, 1.3 \mathrm{mg} / \mathrm{mL}$, [aldehyde] $=$ ca. $90 \mu \mathrm{M})$ in $10 \mathrm{mM}$ phosphate buffer $(\mathrm{pH}=6.5)$, L-tyrosine $(\mathrm{Tyr})$ hydrazide $(10.8 \mathrm{mg}, 55 \mu \mathrm{mol})$ was added, and the reaction mixture was stirred at room temperature for $1 \mathrm{~h}$. Next, sodium cyanoborohydride $(3.5 \mathrm{mg}$, $51 \mu \mathrm{mol})$ was added as a reducing agent to reduce the unstable hydrazone linkage $(\mathrm{C}=\mathrm{N}-\mathrm{NH}-)$, and then the mixture was stirred at room temperature for $24 \mathrm{~h}$. Purification was performed with dialysis against a large quantity of water $(2.0 \mathrm{~L})$ using a pre-swollen semi-permeable membrane (MWCO: 12,000-14,000) for 3 days. The dialysate water was exchanged at 2, 5, 8, 24 and $48 \mathrm{~h}$ after the beginning of dialysis. After purification, $3.0 \mathrm{~mL}$ of the solution was freeze-dried to determine the 
concentration and the degree of the functionality of the Tyr residue in the ${ }^{1} \mathrm{H}-\mathrm{NMR}$ spectra. The ${ }^{1} \mathrm{H}-\mathrm{NMR}$ spectra of the lyophilized NPM or PM micelles in DMSO- $d$ at $80{ }^{\circ} \mathrm{C}$ showed the aromatic protons of the Tyr residue, and the degree of functionality of the Tyr residue of the NPM and PM micelles was $88 \%$ and $83 \%$, respectively, as determined from the peak intensity ratio of the aromatic protons in $\operatorname{Tyr}(\delta 6.8$ and $7.2 \mathrm{ppm})$ to the methine proton in the PLA segment ( $\delta 5.2 \mathrm{ppm})$ of the block copolymer.

\section{Radiolabeling of the Tyr-PM and Tyr-NPM micelles}

A solution of $\mathrm{Na}^{125} \mathrm{I}$ in $10 \mathrm{mM}$ phosphate-buffered saline (PBS) $(15 \mu \mathrm{L}, 74 \mathrm{MBq} / \mathrm{mL}$, PerkinElmer, Inc., USA) was added to a solution of Tyr-labeled NPM or PM micelles in $10 \mathrm{mM}$ PBS (300 $\mu \mathrm{L}$, $2.0 \mathrm{mg} / \mathrm{mL})$. A solution of chloramine $\mathrm{T}$ in $10 \mathrm{mM}$ PBS $(100 \mu \mathrm{L}, 2.0 \mathrm{mM})$ was added to the reaction mixture, which was incubated at room temperature for $10 \mathrm{~min}$. Next, the reaction was quenched by the addition of a solution of sodium peroxodisulfate in $10 \mathrm{mM}$ PBS $(100 \mu \mathrm{L}, 40 \mathrm{mM})$. After shaking for a few minutes, the unreacted ${ }^{125} \mathrm{I}$ and other chemicals were removed by passing the sample through a PD-10 column (GE Healthcare, USA) using PBS as an eluent prior to the biodistribution study. The radioactivity of each fraction was measured using a $\gamma$-counter (Aloka, Japan) (Figure S5). 
Scheme S1. Synthesis of acetal-PEG- $b$-PLA-MA.

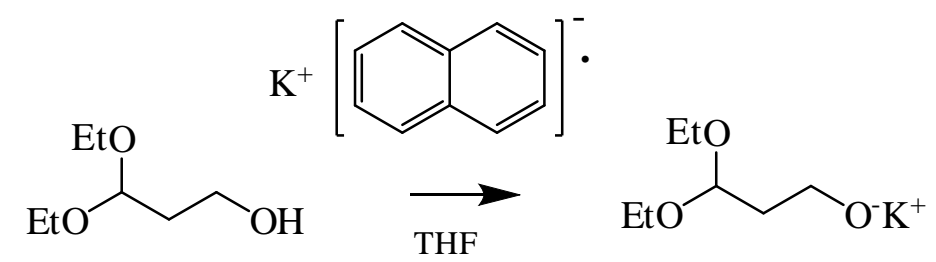

3,3-diethoxy-1-propanol

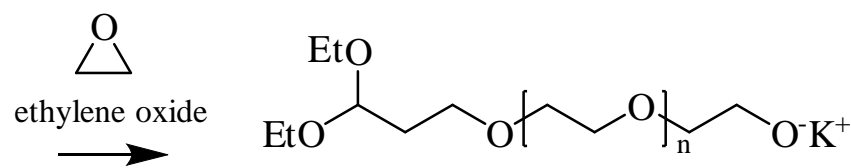<smiles>CC1OC(=O)C(C)OC1=O</smiles>

acetal-PEG

D,L-lactide<smiles>CCOC(CCO[Te]CCOCCOC(=O)C(C)OC(=O)C(C)[OH2+])OCC</smiles>

acetal-PEG- $b$-PLA<smiles>C=C(C)C(=O)OC(=O)C(=C)C</smiles>

methacrylic acid anhydride $\mathrm{EtO}^{-}$<smiles>C=C(C)C(=O)OC(C)C(=O)OCCOCCOCCC(OCC)OCC</smiles>

acetal-PEG- $b$-PLA-MA

Scheme S2. Synthesis of 1-(4-vinylbenzyl)-closo-carborane.
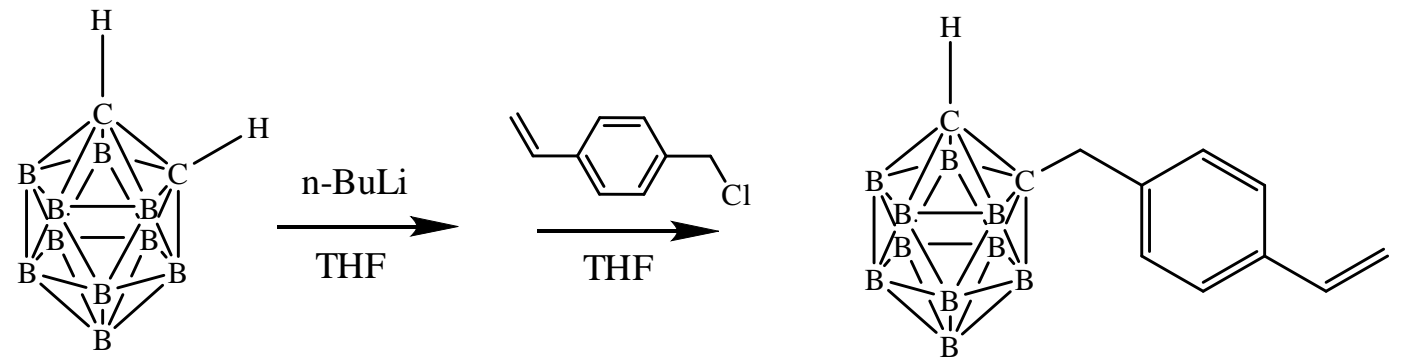


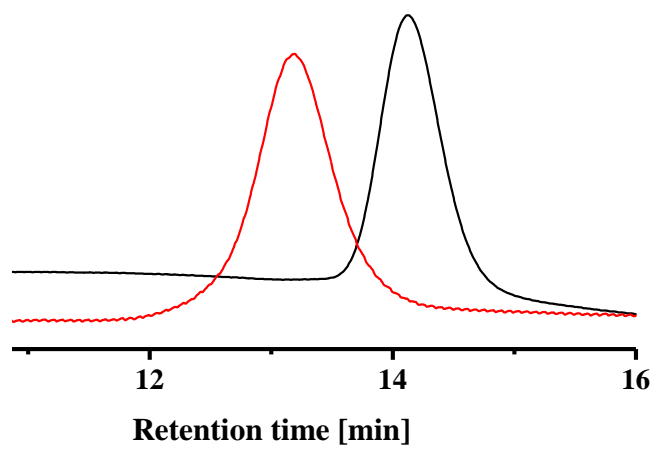

Figure S1. SEC charts of acetal-PEG (black line) and acetal-PEG- $b$-PLA-MA (red line).<smiles>C=C(I)C(=O)OC(C)C(=O)OCCOCCOCCC(OCC)OCC</smiles>

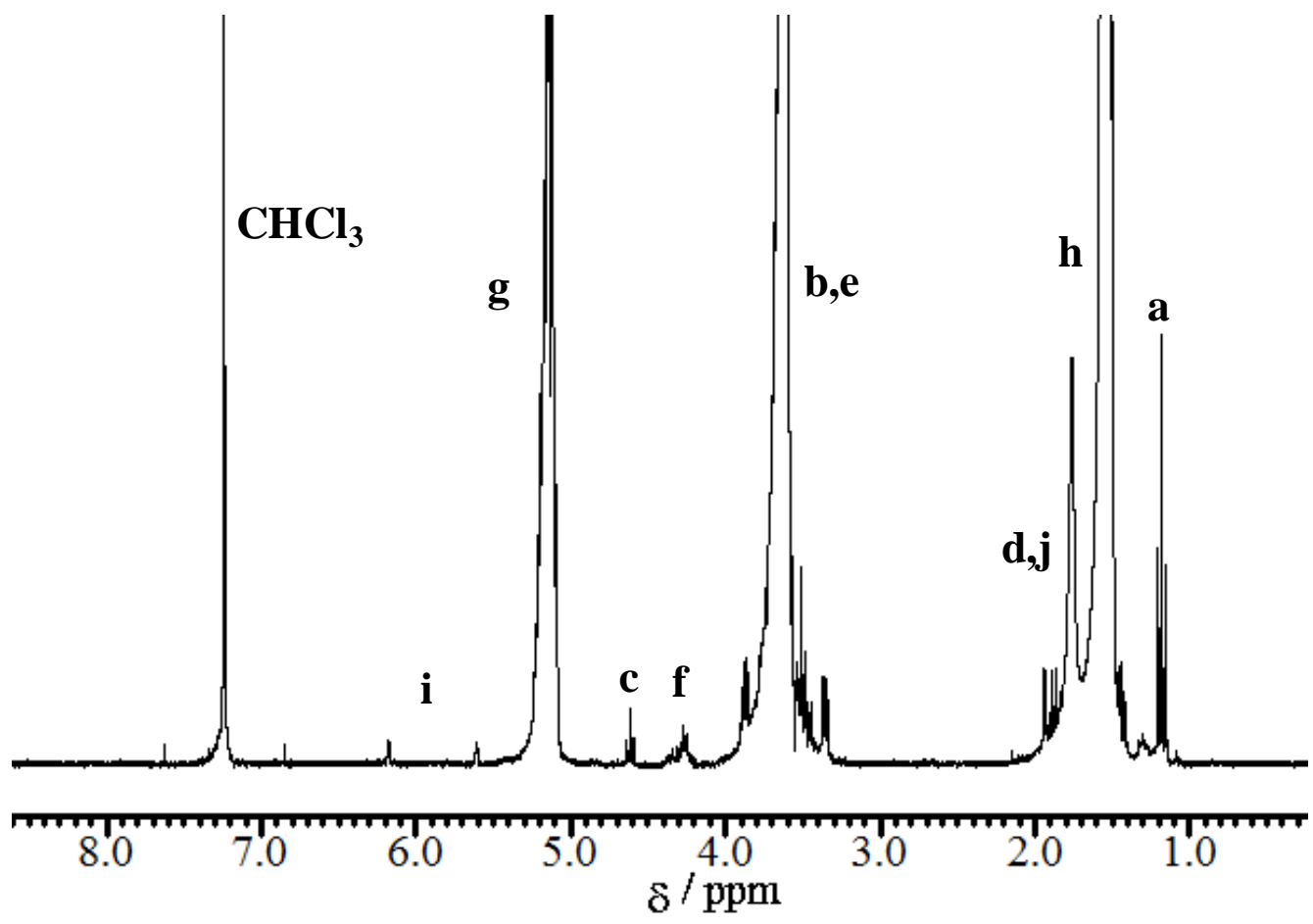

Figure S2. ${ }^{1} \mathrm{H}-\mathrm{NMR}$ spectrum of acetal-PEG- $b$-PLA-MA in $\mathrm{CDCl}_{3}$ at $25{ }^{\circ} \mathrm{C}$. 


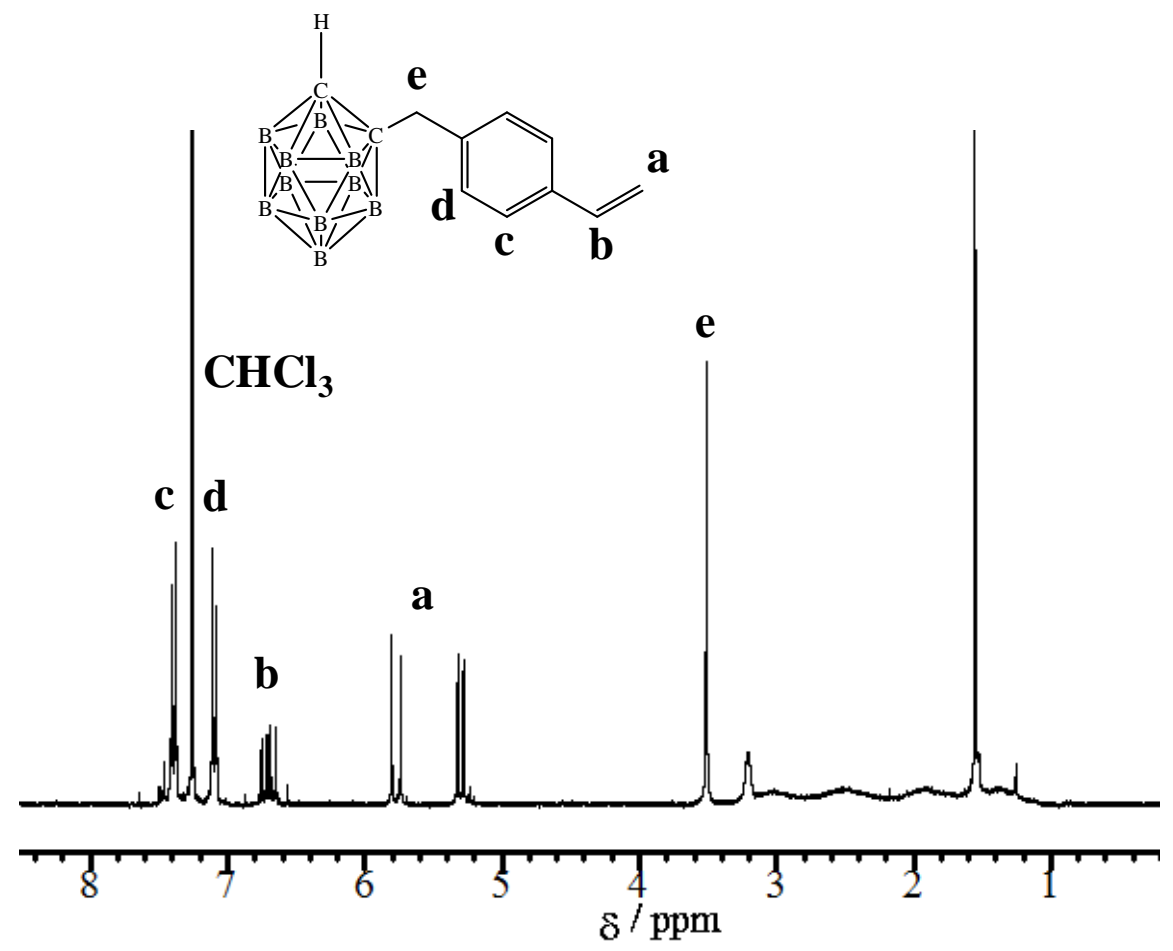

Figure S3. ${ }^{1} \mathrm{H}-\mathrm{NMR}$ spectrum of VB-carborane in $\mathrm{CDCl}_{3}$ at $25^{\circ} \mathrm{C}$.

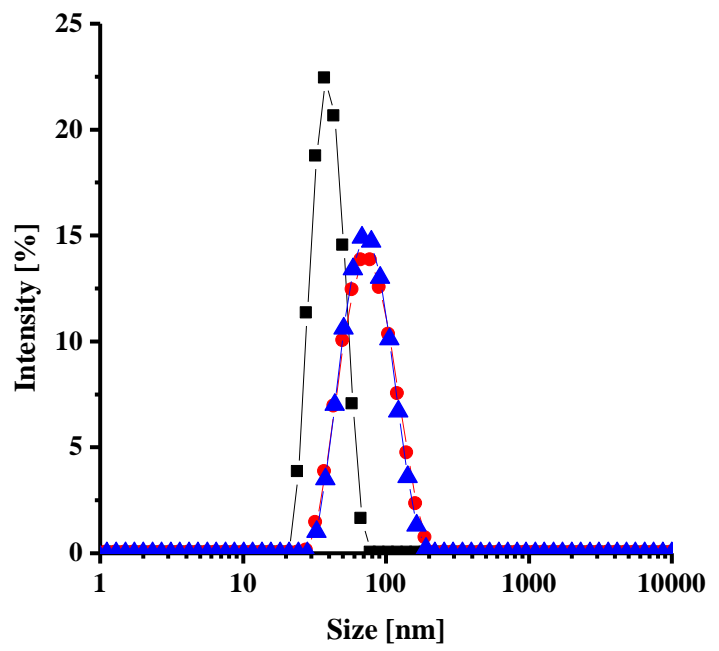

Figure S4. The size distribution of the acetal-PEG- $b$-PLA-MA micelles (black squares), the NPM micelles (red circles) and the PM micelles (blue triangles). 


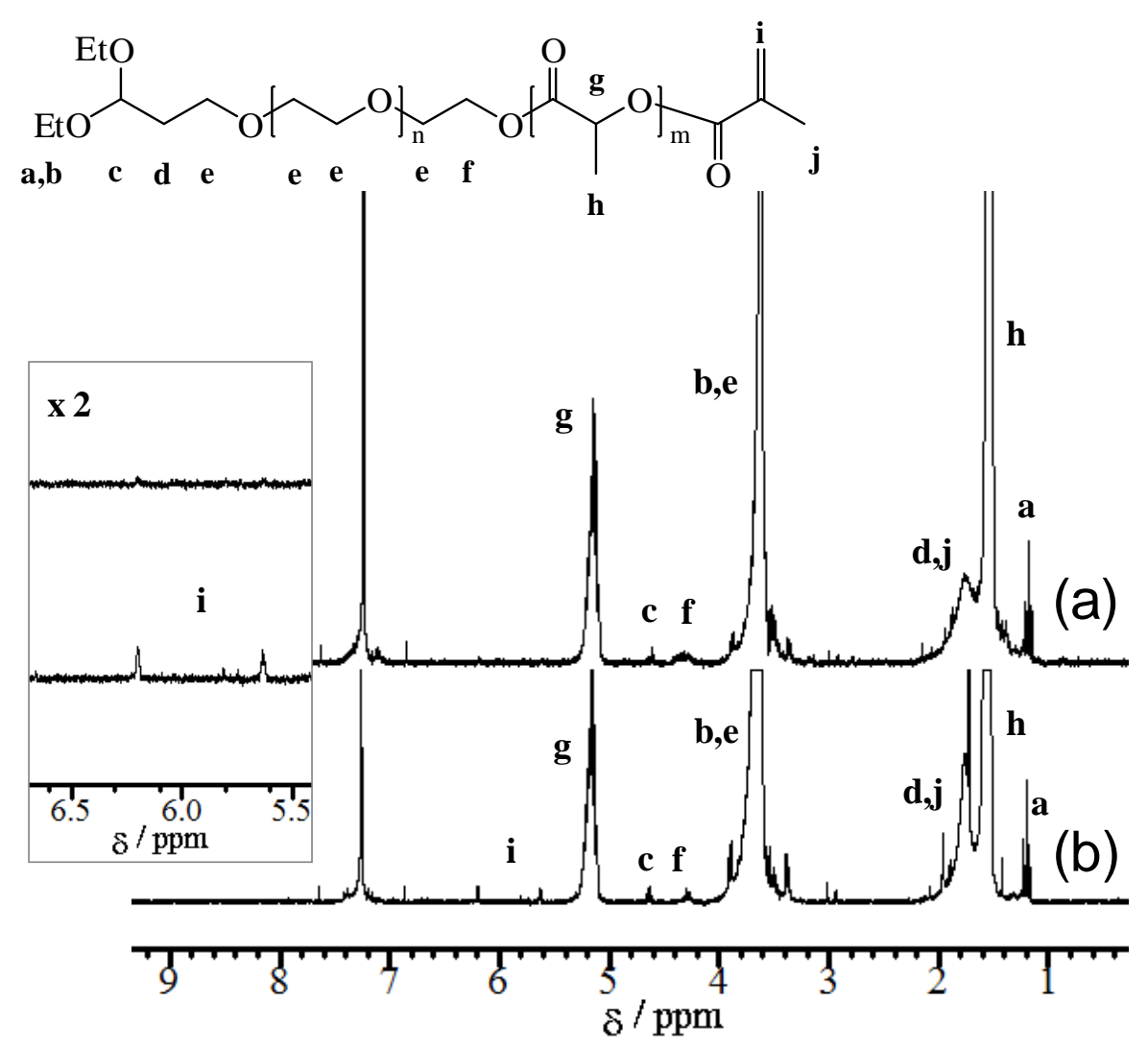

Figure S5. ${ }^{1} \mathrm{H}-\mathrm{NMR}$ spectra of lyophilized PM micelles (a) and NPM micelles (b) in chloroform- $d$.
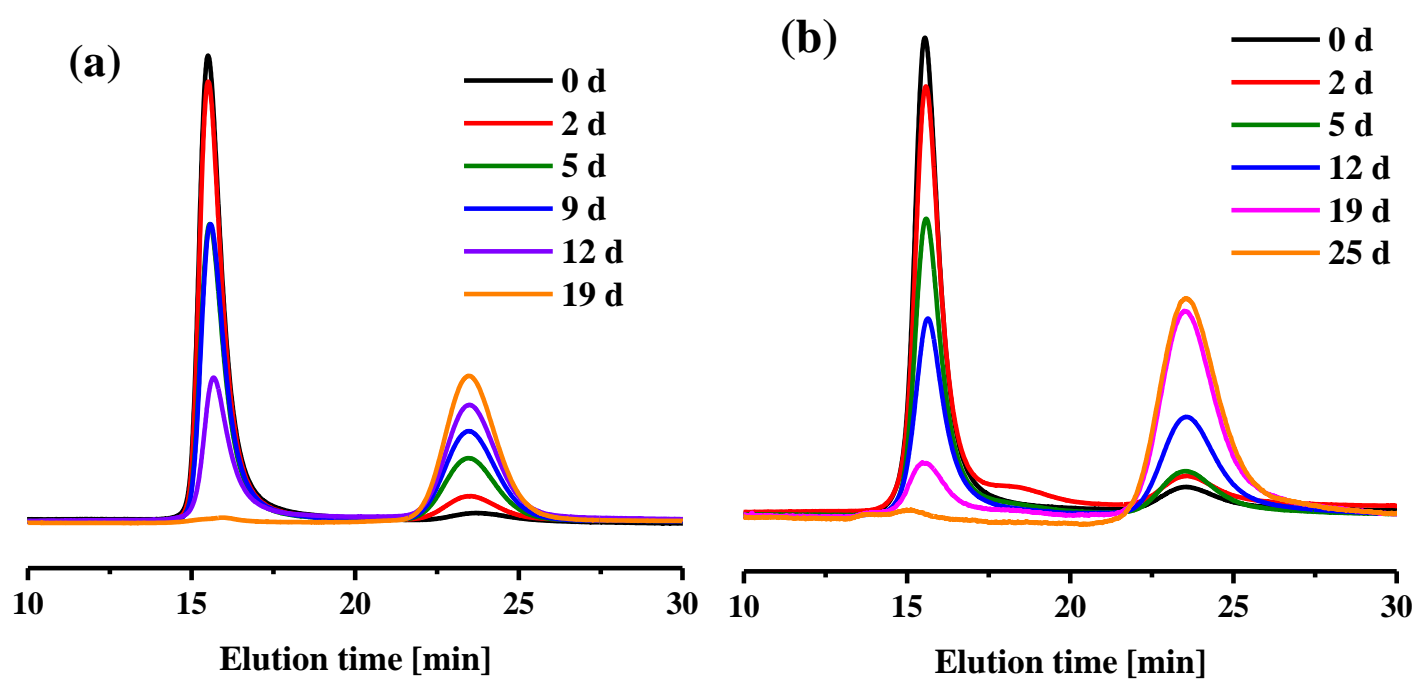

Figure S6. SEC chart changes of the NPM micelles (a) and the PM micelles (b) dependent incubation days in $10 \mathrm{mM}$ PBS at $37^{\circ} \mathrm{C}$. (Column, Superose TM 6 10/300 GL; flow rate, 0.5 $\mathrm{mL} / \mathrm{min}$; eluent, $10 \mathrm{mM}$ phosphate buffer solution, $\mathrm{pH} 7.4$; temperature, $40{ }^{\circ} \mathrm{C}$ ). 


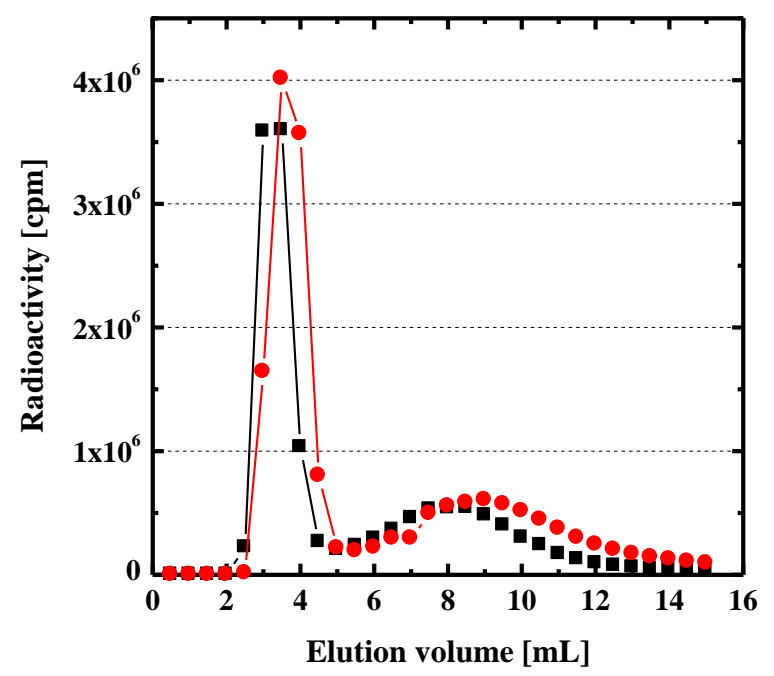

Figure S7. Elution profiles of ${ }^{125}$ I-labeled PM micelles (black squares) and NPM micelles (red circles) in purification through gel filtration chromatography (PD-10 column).

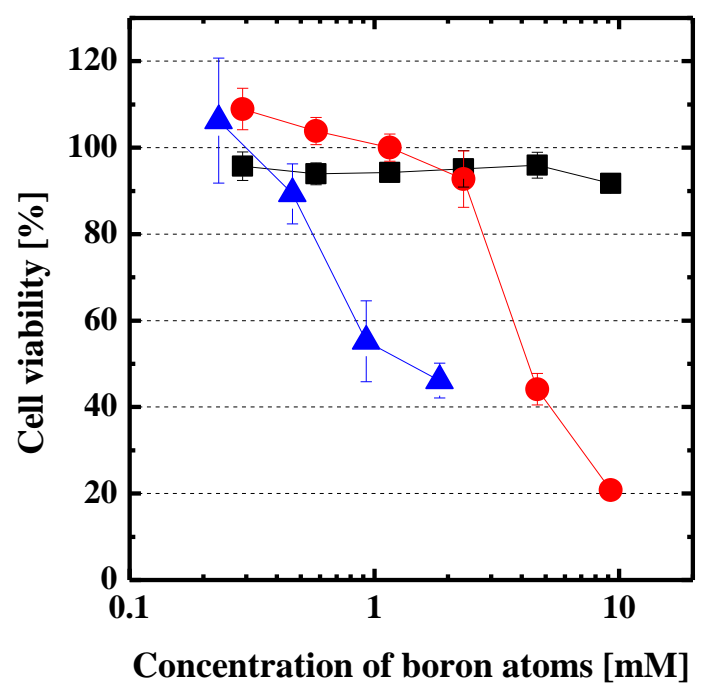

Figure S8. Cytotoxicity of PM micelles (black squares), NPM micelles (red circles), and VB-carborane (blue squares), against colon-26 cells for $24 \mathrm{~h}$. ( $\mathrm{n}=5$, mean $\pm \mathrm{SD})$. 

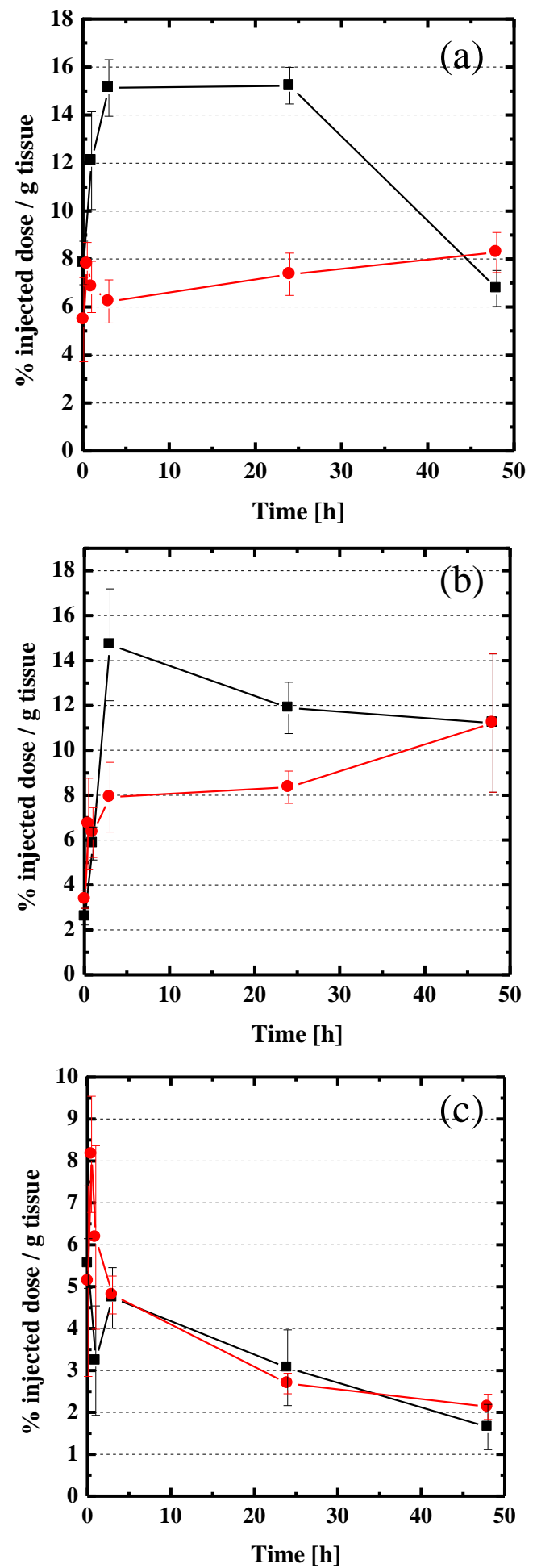

Figure S9. Tissue distribution profiles of the ${ }^{125}$ I-labeled PM micelles (black squares) and the ${ }^{125}$ I-labeled NPM micelles (red circles) in liver (a), spleen (b) and kidney (c) after intravenous injection in tumor-bearing mice, determined based on the radioactivity $(n=3$, mean $\pm S D)$. 

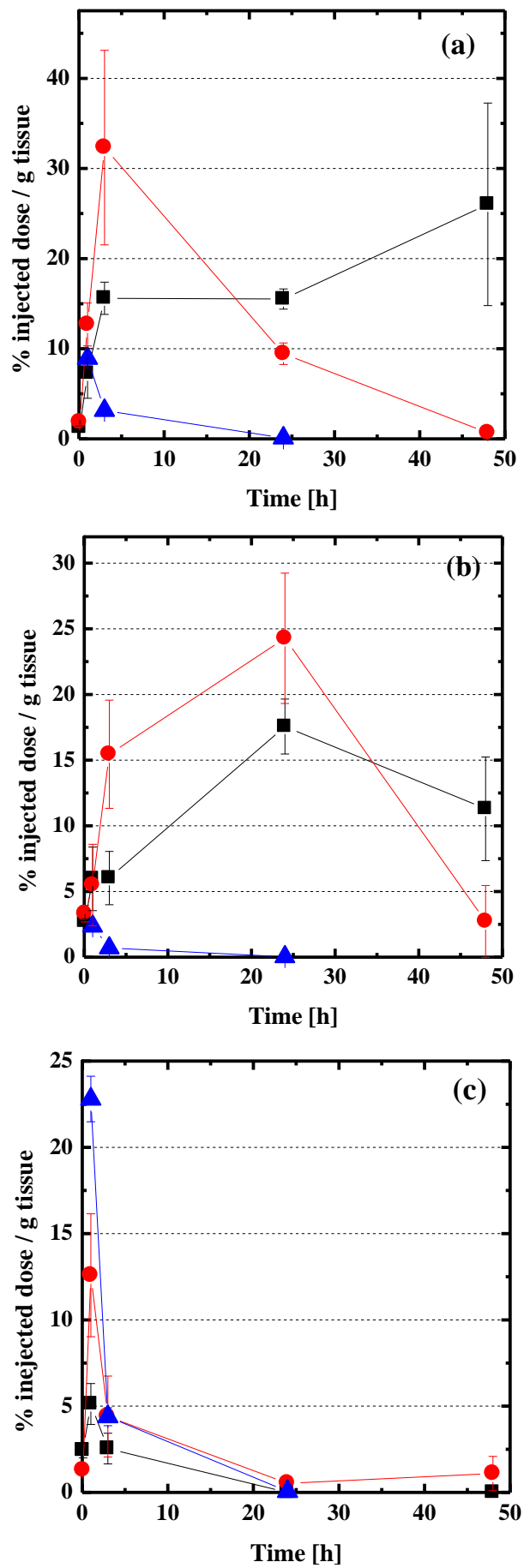

Figure S10. Tissue distribution of the boron species after intravenous injection of the PM micelles (black squares), NPM micelles (red circles) and free BSH (blue triangles) in liver (a), spleen (b) and kidney (c) in tumor-bearing mice, determined by ICP-AES $(n=3$, mean \pm SD). 